\title{
Lugares de reunión, boni homines y presbíteros en Valdevimbre y Ardón en la Alta Edad Media
}

Fernando Luis Corral

\section{(2) OpenEdition}

1 Journals

Edición electrónica

URL: http://journals.openedition.org/medievalista/1093

DOI: 10.4000/medievalista.1093

ISSN: 1646-740X

Editor

Instituto de Estudos Medievais - FCSH-UNL

Referencia electrónica

Fernando Luis Corral, « Lugares de reunión, boni homines y presbíteros en Valdevimbre y Ardón en la Alta Edad Media », Medievalista [En línea], 18 | 2015, Publicado el 01 junio 2015, consultado el 16 marzo 2020. URL : http://journals.openedition.org/medievalista/1093 ; DOI : https://doi.org/10.4000/ medievalista.1093

\section{(c) (†) \&)}

Mediavalista está licenciado com uma Licença Creative Commons - Atribuição-NãoComercial 4.0 Internacional. 
Título: Lugares de reunión, boni homines y presbíteros en Valdevimbre y Ardón en la Alta Edad Media

Autor(es): Fernando Luis Corral

Universidade: Universidad de Salamanca

Faculdade e Departamento / Unidade de Investigação: Facultad de Geografía e Historia

/ Departamento de Historia Medieval, Moderna y Contemporánea

Código Postal: 37002

Cidade: Salamanca

País: España

Contacto: fcorral@usal.es

Fonte: Medievalista [Em linha]. Direc. José Mattoso. Lisboa: IEM.

Disponível em:

http://www2.fcsh.unl.pt/iem/medievalista/MEDIEVALISTA18/corral1805.html

ISSN: 1646-740X

Data recepção do artigo: 14 de Novembro de 2014

Data aceitação do artigo: 27 de Fevereiro de 2015

\section{Resumo}

El objetivo de este artículo es entender mejor algunos aspectos del desarrollo social y político de las comunidades campesinas de la zona de Ardón y Valdevimbre (al sur de la ciudad de León) en la Alta Edad Media. Los documentos leoneses del siglo X y de la primera mitad del siglo XI nos ofrecen la oportunidad de conocer a algunos miembros de las elites locales a través de reiteradas menciones de boni homines y presbíteros que aparecen en ellos. Este hecho nos está informando de la creciente desigualdad social que se produjo en el seno de estas comunidades. Pero además, la documentación nos informa de la dimensión política de las relaciones de estas comunidades con algunas instituciones eclesiásticas y magnates y, a través de ellos, con el poder central asturleonés, analizando los cambios de ubicación de los lugares de reunión para la resolución 
de conflictos surgidos entre los miembros de las comunidades y los de estas elites de poder.

Palavras-chave: Boni homines, presbítero, comunidad local, conflicto, Alta Edad Media, Ardón, Valdevimbre.

\section{Abstract}

The aim of this article is to better understand some features of the social and political development of the peasant communities located at the area of Ardón and Valdevimbre (south of the city of León, Spain) in the Early Middle Ages. Leonese charters from $10^{\text {th }} .-11^{\text {th }}$. centuries shows us the opportunity to know some of the local elite members, if we pay attention to repeated mentions of boni homines (good men) and local priests who appear on these charters. This fact reports us about the increasing social inequality produced inside these peasant communities.

We will also explore changes in location of meeting places chosen to solve conflicts between community members and the ones of some ecclesiastical institutions and aristocracy as a way to better know the political side of the relationship between the mentioned peasant communities and those power elites and, through them, with the Astur-leonese central power.

Keywords: Boni homines, local priest, local community, conflict, Early Middle Ages, Ardón, Valdevimbre. 


\section{Lugares de reunión, boni homines y presbíteros en}

\section{Valdevimbre y Ardón en la Alta Edad Media*.}

Fernando Luis Corral

La consolidación de León como centro de poder a partir del siglo X, facilitó paulatinamente la integración en el marco político de la monarquía astur-leonesa de las comunidades campesinas que se hallaban en el territorio más al sur de la urbe ${ }^{1}$. Los diplomas leoneses que hacen mención a la zona del Páramo, más concretamente a la zona de Ardón y Valdevimbre, nos sitúan en el siglo X en un escenario donde algunos grupos de poder eclesiástico conectados con el poder central se estaban relacionando con las sociedades locales circundantes.

\footnotetext{
* Este trabajo ha sido realizado en el marco del proyecto de investigación "Territorios e identidades locales en el centro de la Península Ibérica altomedieval: análisis espacial de las tumbas excavadas en roca” (Ref.: HAR2010-21950-C03-02/HIST). Quiero expresar mi agradecimiento a Álvaro Carvajal Castro, Wendy Davies, Iñaki Martín Viso y María Pérez Rodríguez por las sugerencias que me han hecho sobre distintos aspectos de los borradores de este trabajo.

${ }^{1}$ MÍNGUEZ FERNÁNDEZ, José María - "Poderes locales en el espacio central leonés durante el periodo astur”. Territorio, Sociedad y Poder. Oviedo. Anejo 2 (2009), p. 205. Sobre la consolidación de León como centro de poder regio, es interesante ver CARVAJAL CASTRO, Álvaro - "La construcción de una sede regia: León y la identidad política de los reyes asturleoneses en la crónica de Sampiro y en los documentos”. e-Spania [en ligne]. 18 (junio 2014). 4 Jun. 2014 [Consult. 3 Sept. 2014]. Disponible en http://e-spania.revues.org/23714; DOI: 10.4000/e-spania.23714.
}

Medievalista online № 18| Julho - Dezembro 2015 ๑ IEM - Instituto de Estudos Medievais 3 www2.fcsh.unl.pt/iem/medievalista 


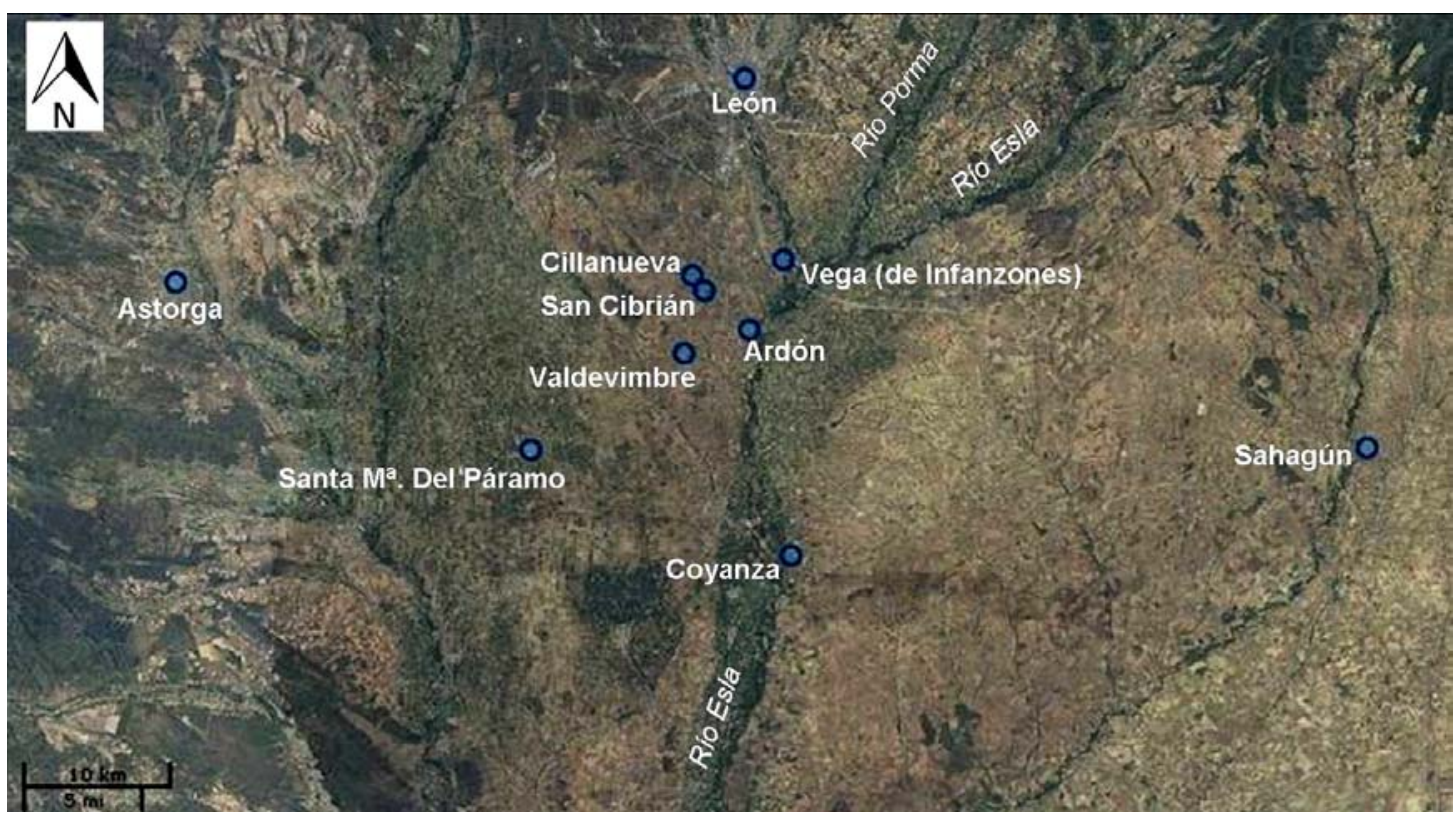

Fig. 1. Mapa del área de Valdevimbre y Ardón.

La relación con estos grupos de poder mencionados fue la vía a través de la cual estas comunidades campesinas entraron progresivamente en un contacto más directo con la monarquía astur-leonesa en su proceso de expansión política sobre el territorio y fueron integrándose en su esfera de control político. Los diplomas nos muestran a los monasterios de los Santos Justo y Pastor de Ardón y al monasterio de Santiago y Santa María de Valdevimbre actuando en estos espacios desde inicios del siglo $\mathrm{X}^{2}$. Estos

${ }^{2}$ En el caso del monasterio de Valdevimbre desde el año 915, que es cuando tenemos la primera referencia documental del cenobio, aunque a la luz de lo que nos relata este documento, su actividad podría haber comenzado antes. En el caso del monasterio de Ardón, la primera mención se retrasa unos años más y nos lleva a la primavera del año 932, aunque podría ocurrir que, como en el caso de Valdevimbre, la actividad del monasterio en la zona fuera anterior, vid. SÁEZ, Emilio - Colección documental del archivo de la Catedral de León (775-1230), I (775-952). León: Centro de Estudios e Investigación San Isidoro, 1987, doc. 34 y doc. 123 (en adelante = CatLeón I). No poseemos ningún documento fundacional de los dos monasterios, ni tampoco referencias verosímiles de la fecha de su fundación, lo que dificulta conocer el momento inicial de su andadura, o si nacieron en el seno de alguna de las comunidades locales promovidos por algún grupo de poder de la propia comunidad o fueron fundaciones de aristocracias ajenas a esas comunidades aldeanas de la zona. No parecen ser fundaciones regias, aunque se produjera una relación entre estas instituciones eclesiásticas y la propia monarquía. Sobre el monasterio de los Santos Justo y Pastor de Ardón, véase RODRÍGUEZ FERNÁNDEZ, Justiniano - El monasterio de Ardón. Estudio histórico sobre los centros monásticos medievales de Cillanueva y Rozuela. León: Centro de Estudios e Investigación de San Isidoro, 1964. Otros trabajos sobre este monasterio son el de VILLALOBOS, María Luisa y GONZÁLEZ, J. Ignacio - "San Justo y Pastor de Ardón. Problemas históricos y patrimonio monástico". in Semana de Historia del Monacato Cántabro-Astur-Leonés. Oviedo, 1982, pp. 155-173; o el de FERNÁNDEZ CATÓN, José María - “La nodicia de kesos y los problemas de la documentación del siglo X sobre el origen de los monasterios independientes de Rozuela y Cillanueva”. in Orígenes de las lenguas romances en el reino de León, siglos IX-XII, vol. I. León: Centro de Estudios e Investigación San Isidoro, 2004, pp. 35-85. En los

Medievalista online № 18| Julho - Dezembro 2015 (c) IEM - Instituto de Estudos Medievais 4 www2.fcsh.unl.pt/iem/medievalista 
documentos en los que se describe a ambas instituciones eclesiásticas relacionándose con gentes que tenían propiedades en la zona de Valdevimbre y Ardón, no definen una situación en la que podamos advertir una reciente instalación en estos espacios de los campesinos con los que litigaron o de los que recibieron una donación. Por ejemplo, la presa y el molino construido por Vímara y sus hijos, o los bienes que el presbítero Benedicto y su madre tenían en las villas de Matilla y Morilla compuestas de casas, terras, uineas, ortos, pomares siue pratis, no parecen ser las propiedades de campesinos que tuvieran un nivel de vida cercano a la subsistencia ${ }^{3}$. Al contrario, lo que se percibe es que en estas comunidades locales había miembros que habían acumulado un patrimonio relativamente importante, diferenciándose así del resto de los integrantes de éstas ${ }^{4}$. Este hecho les ponía en una posición idónea para relacionarse de diversas maneras con otros grupos de poder, como las instituciones eclesiásticas mencionadas, que a su vez estaban conectadas con el poder central y sentían una especial apetencia por adquirir ese tipo de propiedades por sus posibilidades de explotación de recursos naturales y la consiguiente transformación de materias primas, o por la producción de esas materias primas. De manera que nos encontramos con comunidades campesinas ya consolidadas en la zona, que en su seno albergan a algunos miembros que han acumulado un patrimonio personal relativamente importante fruto de la explotación de

trabajos mencionados se refiere también el debate abierto sobre la duplicidad de sedes del monasterio de los Santos Justo y Pastor, aunque la mayor parte de los autores coinciden en ver un solo monasterio con varias sedes y una misma advocación. El estudio del monasterio de Valdevimbre ha sido abordado por ÁLVAREZ ÁLVAREZ, César - "El monasterio de Valdevimbre (siglos IX-XII)". in DÍAZ Y DÍAZ, Manuel y DÍAZ DE BUSTAMANTE, Mercedes (eds.) - Estudios dedicados a José María Fernández Catón. León: Centro de Estudios e Investigación San Isidoro, 2004, pp. 41-64. Existe un documento del año 975 que identifica a un tal conde Berulfo como fundador del monasterio de Ardón, pero el documento en el que se plantea esto parece ser falso y, por tanto, poco creíble la noticia acerca del conde Berulfo, vid. VALDÉS GALLEGO, Juan Antonio - El Liber Testamentorum Ovetensis. Estudio filológico y edición. Oviedo: Real Instituto de Estudios Asturianos, 1999, pp. 532-34. F. J. Fernández Conde lo considera falso, así como E. Sáez y A. Sánchez Candeira, véase FERNÁNDEZ CONDE, Francisco Javier - El Libro de los Testamentos de la Catedral de Oviedo. Roma: Iglesia Nacional Española, 1971, p. 199 y nota $\mathrm{n}^{\mathrm{o}} 10$.

${ }^{3}$ CatLeón I, doc. 34 y doc. 93.

${ }^{4}$ I. Martín Viso insiste en este aspecto cuando considera que "las comunidades de aldea no eran entes igualitarios y que en su interior cohabitaban personas con patrimonios muy diversos y con estatus diferenciados”, vid. MARTÍN VISO, Iñaki - Fragmentos del Leviatán. La articulación política del espacio zamorano en la Alta Edad Media. Zamora: Instituto de Estudios zamoranos "Florián de Ocampo", 2002, p. 79.

Medievalista online № 18| Julho - Dezembro 2015 @ IEM - Instituto de Estudos Medievais 5 www2.fcsh.unl.pt/iem/medievalista 
los recursos del propio paisaje, poniendo de manifiesto la creciente desigualdad social que se había generado en el seno de estas comunidades ${ }^{5}$.

Sabemos que las comunidades campesinas y algunos de estos grupos de poder ya mencionados protagonizaron conflictos derivados de la explotación y control de los recursos naturales y del espacio en torno a Ardón y Valdevimbre. ${ }^{6}$ Disputas que no fueron privativas de este espacio en particular, sino que se repitieron en otras zonas de la península, pero también en otras zonas europeas ${ }^{7}$. Algunos de esos conflictos se solucionaron a través de litigios que, en la mayor parte de las ocasiones, beneficiaron a las elites $\mathrm{y}$, fruto de ello, se fue transformando el equilibrio que esas comunidades mantenían con la explotación de los medios naturales de su entorno. Es esta "justicia de clase”, así denominada por J. Ma. Salrach o C. Wickham ${ }^{8}$, que benefició fundamentalmente a la aristocracia laica y eclesiástica que iba penetrando en los espacios controlados hasta entonces por las sociedades locales, la que también nos permite ver, a través de los procesos judiciales descritos en los documentos, que estas comunidades estaban ya a finales del siglo X y sobre todo en el siglo XI en un proceso de diferenciación social bastante avanzado.

Los diplomas leoneses del siglo X y de la primera mitad del siglo XI -que son con los que vamos a trabajar en este estudio referido a la zona de Ardón y Valdevimbre- nos informan de varios aspectos que ilustran la desigualdad social que se ha ido produciendo en el seno de las comunidades aldeanas ${ }^{9}$. Por un lado, la aparición reiterativa de presbíteros con un patrimonio personal que en la mayoría de los casos era

\footnotetext{
${ }^{5}$ El proceso de diferenciación social de las comunidades locales es general y afectó de forma similar a otros espacios. Para la zona castellana, vid. ÁLVAREZ BORGE, Ignacio - Poder y relaciones sociales en Castilla en la Edad Media. Los terriotiros entre el Arlanzón y el Duero en los siglos X al XIV. Salamanca: Junta de Castilla y León, 1996, pp. 27-51.

${ }^{6}$ CatLeón I, doc. 125.

${ }^{7}$ DAVIES, Wendy - "Settling Disputes in Early Medieval Spain and Portugal: a Contrast with Wales and Brittany?”. in GRIFFITHS, Ralph A., SCHOFIELD, Phillipp R. (eds.) - Wales and the Welsh in the Middle Ages. Cardiff: University of Wales Press, 2011, pp. 92-93.

${ }^{8}$ SALRACH, José María - "Prácticas judiciales, transformación social y acción política en Cataluña (siglos IX-XIII)”. Hispania. Madrid. LVII/3, 197 (1997), pp. 1022-1023; y WICKHAM, Chris - "Espacio y sociedad en los conflictos campesinos en la Alta Edad Media”. in RODRÍGUEZ, Ana (ed.) - El lugar del campesino. En torno a la obra de Reyna Pastor. Valencia: Universitat de València y CSIC, 2007, p. 35.

${ }^{9}$ Las principales fuentes en las que los monasterios de Ardón y Valdevimbre se hacen visibles son los documentos de los siglos X y XI que se encuentran en el archivo de la Catedral de León y que han sido publicados por Emilio Sáez, Carlos Sáez y José Manuel Ruiz Asencio, como puede verse en la bibliografía al final del trabajo.
}

Medievalista online № 18| Julho - Dezembro 2015 ๑ IEM - Instituto de Estudos Medievais 6 www2.fcsh.unl.pt/iem/medievalista 
importante. Por otro lado, conectado también con ese aspecto de la desigualdad social pero también con la resolución de conflictos y la aplicación de la justicia, la aparición de un grupo de personas que actuaban -principalmente- como mediadores entre las bases sociales campesinas de esas comunidades y las elites a las que nos hemos referido: los boni homines. Y un tercer aspecto que está conectado con la resolución de conflictos es la elección del lugar donde se habrían de resolver las disputas que afectaban a los integrantes de las comunidades campesinas y a los miembros de las elites que se relacionaban con esas sociedades locales.

La resolución de litigios, comúnmente favorables a estas elites mencionadas de forma genérica, también nos informa del funcionamiento político de las comunidades locales y de las posibles transformaciones que se pudieron operar en los lugares de referencia de la memoria social de éstas. $\mathrm{Y}$ en este sentido, ¿en qué lugares se resolvieron las desavenencias que se produjeron entre los miembros de las diferentes comunidades campesinas de la zona de Ardón y Valdevimbre? La documentación, a día de hoy, no permite resolver de forma concluyente este interrogante y sólo cabe presumir que, posiblemente, cada comunidad resolvió sus problemas de forma pública reuniéndose en un lugar conocido por todos sus miembros dentro del espacio aldeano. Lo más probable, como sucedió en otros territorios, es que la iglesia del lugar se convirtiera en el espacio central donde la asamblea de vecinos se reuniera para solventar los problemas que surgieran dentro de la comunidad o tomar decisiones sobre los aprovechamientos colectivos del campo, etc ${ }^{10}$. A la vez, con el avance del proceso de desigualdad social

\footnotetext{
${ }^{10}$ PORTELA, Ermelindo y PALLARES, Ma . Carmen - "La villa por dentro. Testimonios galaicos de los siglos X y XI”. Studia Historica. Historia Medieval. Salamanca. 16 (1998), pp. 41-42. W. Davies planteaba en su estudio sobre la Bretaña altomedieval que las "transactions were often performed in or in front of the local church and dispute proceedings might be conducted there. Lay men might buy and sell to each other or oaths might be taken by witnesses there, sometimes specifically on the altar", vid. DAVIES, Wendy - Small Worlds: The Village Community in Early Medieval Brittany. Berkeley-Los Angeles: University of California Press, 1988, p. 81. J. C. Sánchez también señala que esta utilización de la iglesia como lugar de reunión de la asamblea vecinal de la sociedad local no era algo privativo de la Península, sino que se dio en otros ámbitos de Europa, como en la zona de la Toscana, vid. SÁNCHEZ PARDO, José Carlos - Territorio y poblamiento en Galicia entre la Antigüedad y la Plena Edad Media. Santiago de Compostela: Servicio de Publicaciones de la Universidad de Santiago de Compostela, 2008. Tesis doctoral publicada en CD. [Consult. On-line 08 Agost. 2014], p. 518. R. McKitterick plantea también esta simbiosis en el mundo carolingio entre la iglesia o el monasterio y la comunidad local que acudía a las dependencias eclesiásticas y allí celebraba sus reuniones para resolver cuestiones judiciales, ya que la institución brindaba un marco más que válido para asegurarse la observancia de la ley y que los negocios allí resueltos se hacían públicos para toda la comunidad, vid. MCKITTERICK, Rosamond - The Carolingians and the Written Word. Cambridge: Cambridge University Press, 1995, p. 125.
}

Medievalista online № 18| Julho - Dezembro 2015 ๑ IEM - Instituto de Estudos Medievais 7 www2.fcsh.unl.pt/iem/medievalista 
dentro de las comunidades y también una vez que se comenzaron a consolidar elites laicas o eclesiásticas en la zona de Valdevimbre y Ardón, éstos pudieron forzar, cuando ellos lo consideraron conveniente, el cambio de lugar escogido para la celebración de los litigios donde ellos tenían intereses. En ocasiones las asambleas se celebraron en un lugar cercano o en el mismo lugar por el que se había generado el desacuerdo, si ese poder externo tenía intereses consolidados allí $^{11}$; en otras ocasiones, el lugar escogido soportó un mayor radio de distancia respecto del enclave donde se originó la disputa y se localizó en espacios donde el poder central o aristocrático estaba sólidamente representado en detrimento de la comunidad, o mejor dicho, de los miembros de la comunidad que pleiteaban, y que veían así alterada su posición de fuerza frente a estos grupos de poder.

Una vez que a partir del siglo X comenzamos a tener noticias, a través de los diplomas, de las sociedades locales del espacio circundante a Valdevimbre y Ardón, lo que se observa es que, en la mayor parte de los casos, cuando se nos informa de algún lugar de reunión para solventar conflictos, León fue la ubicación preferida ${ }^{12}$. La documentación conservada nos permite conocer varios ejemplos al respecto. Uno de ellos fue el litigio allí celebrado en el año 915 en presencia del obispo Fruminio y los jueces Vegila, Hatec y Recemiro, que enfrentó al monasterio de Valdevimbre y su abad Balderedo contra

\footnotetext{
${ }^{11}$ Una de las referencias documentales más antiguas sobre este aspecto está recogida en el Tumbo de San Martín de Castañeda en el año 927 y narra el juicio que mantuvo el monasterio de Castañeda contra Ranosindo y sus gasalianes por la posesión de unas pesqueras en Galende, en el territorio de Sanabria (Zamora), vid. RODRÍGUEZ GONZÁLEZ, Ángel - "El tumbo del monasterio de San Martín de Castañeda”. Archivos Leoneses. León. 39-40 (1966), doc. 1. I. Martín Viso ha estudiado este documento en el que el lugar escogido para el juicio no fue ni el lugar donde se produce la desavenencia, ni tampoco el propio monasterio de San Martín de Castañeda, sino en la iglesia de San Pedro de Valdespino, un lugar que Martín Viso plantea que era reconocido como propio por la comunidad local, aunque, eso sí, en un espacio eclesial, vid. MARTÍN VISO, Iñaki - "La feudalización del Valle de Sanabria (siglos X-XIII)". Studia Historica. Historia Medieval. Salamanca. 11 (1993), pp. 38-40. Este tema también lo plantea J. M. Andrade al referirse a algunos de los lugares escogidos para la celebración de juicios en los que el monasterio de Samos estuvo involucrado: como el que le llevó a pleitear por la villa de Requejo en 1075 y que se celebró en Triacastella, próximo a la villa que motivaba la disputa y un lugar donde Samos tenía muchos intereses, vid. ANDRADE, José Manuel - "Villas regias y asambleas judiciales entre los siglos X y XI: el caso de Larín”. Signum. Pampulha-Belo Horizonte. 12, n. 2 (2011), p. 25. Fuera de la zona gallega también se dan estos casos, como el litigio que se resolvió en Villacorta entre Pedro Ovéquiz y Suero Eriz en 1037 por unas propiedades en este mismo lugar, vid. HERRERO DE LA FUENTE, Marta - Colección diplomática del monasterio de Sahagún (857-1230), II (1000-1073). León: Centro de Estudios e Investigación San Isidoro, 1988, doc. 451.

12 J. M. Andrade en su análisis sobre el caso de Larín, define los lugares como León o algunas ciudades episcopales como "previsibles", vid. ANDRADE, José Manuel - "Villas regias y asambleas judiciales entre los siglos X y XI: el caso de Larín”. Signum. Pampulha-Belo Horizonte. 12, n. 2 (2011), p. 24.
}

Medievalista online № 18| Julho - Dezembro 2015 ๑ IEM - Instituto de Estudos Medievais 8 www2.fcsh.unl.pt/iem/medievalista 
Munio y sus hermanos por una presa que este último había construido quitándole el agua a los molinos del monasterio durante tres meses ${ }^{13}$. In presencia iudicum magnatorumque legionensium en el año 941 se produjo la vista de un pleito entre el presbítero Nemorelli y de nuevo el abad Balderedo por la propiedad de otros molinos situados estos entre los ríos Torío y Bernesga ${ }^{14}$. También en León en el año 946 se firmó un placitum surgido del litigio entre el monasterio de los Santos Justo y Pastor de Ardón y Mateo, que se había apoderado de la iglesia de San Esteban de Mazules y había agredido a los hombres del monasterio varias veces ${ }^{15}$. A León se vieron obligados a desplazarse en el año 952 Munio y Lup para litigar por una tierra en el valle de Mahamut ante el conde Velasco ${ }^{16}$. En León también se reunió en el 954 un concilio que tuvo que dirimir otro conflicto originado por la anulación de la donación de las propiedades que el presbítero Julián había entregado al monasterio de Valdesaz debido a la mala conducta de los monjes y monjas y poder, a continuación y tras la resolución del concilio, donarlas al monasterio de los Santos Justo y Pastor de Ardón ${ }^{17}$. Un diploma de 959 nos informa de nuevo de un contencioso celebrado en León entre el abad Lázaro y la abadesa Purísima contra el monasterio de los Santos Justo y Pastor por la posesión de unas tierras que habían sido donadas a este monasterio. El proceso, que se alargó en el tiempo, fue presidido en distintas fases por el obispo de la ciudad y por el iudex Abaiub, saliendo bien parado el monasterio ${ }^{18}$. Como se puede apreciar, ya fuera porque la causa del litigio tenía una cierta importancia o, sobre todo, cuando los intervinientes en los procesos eran de una categoría relevante, parece que León fue un lugar recurrente a la hora de albergar estos procesos judiciales. Instituciones importantes como los monasterios de Valdevimbre y Ardón, o personajes destacados de sus comunidades como los presbíteros Nemorelli o Julián, o los abades Lázaro y Purísima litigaron por propiedades importantes; pero también lo hicieron miembros de las comunidades que se

\footnotetext{
${ }^{13}$ CatLeón I, doc. 34.

${ }^{14}$ CatLeón I, doc. 144.

15 CatLeón I, doc. 192. La iglesia de San Esteban de Mazul había llegado a manos del monasterio de Ardón a través de dos donaciones en los años 943 y 944, vid. CatLeón I, docs. 176 y 186.

${ }^{16}$ CatLeón I, doc. 243.

17 SÁEZ, Emilio y SÁEZ, Carlos - Colección documental del archivo de la Catedral de León (775-1230), II (935-985). León: Centro de Estudios e Investigación San Isidoro, 1987, doc. 278 (en adelante=CatLeón II).

${ }^{18}$ CatLeón II, doc. 312.
}

Medievalista online $N^{\circ} 18 \mid$ Julho - Dezembro 2015 ๑ IEM - Instituto de Estudos Medievais 9 www2.fcsh.unl.pt/iem/medievalista 
vieron obligados a comparecer en estos tribunales de la sede regia leonesa, un tanto alejados de sus poblaciones de origen, para reclamar propiedades de la zona.

Aunque son mayoritarios los ejemplos mencionados ubicados en la capital leonesa, la documentación guarda también algún ejemplo de conflictos solventados en otros espacios de reunión. Uno de ellos nos remite al ámbito monástico, puesto que las propiedades objeto de la disputa entre el monasterio y algunos miembros de una comunidad aldeana, pertenecían a los monjes. Nos referimos al documento en el que se nos relatan las vicisitudes de Godesteo y Aluito, quienes mantuvieron una “desavenencia” con el monasterio de los Santos Justo y Pastor por talar unos árboles que eran propiedad de los monjes. Ambos firmaron un documento in conuentu ecclesia sancti Iusti et Pastoris en el que se comprometían a la entrega de unas tierras qui pectauimus pro nostras facinoras, consiguiendo el cenobio que éstos se sometieran a las condiciones impuestas por el monasterio en sus propias dependencias como espacio idóneo donde escenificar su dominio ${ }^{19}$. Algunos investigadores han planteado que la utilización de iglesias como marco de celebración de litigios estaría detrás de la búsqueda de una dimensión sagrada que obligara a los hombres a obrar rectamente y ser fieles a la verdad ${ }^{20}$. Sin descartar este argumento, parece que este cambio de escenario buscara, más que nada, hacer pública y visible la fuerza y el prestigio del monasterio en el espacio en el que estaba implantado de cara a que la comunidad y sus integrantes fueran conscientes de esa preeminencia y del coste económico que podría suponer hacerles frente. El sentido de publicidad entre los miembros de la comunidad y, a la vez, esa otra dimensión de otorgar garantías de cumplimiento de lo estipulado entre las partes se observa en otros ejemplos en los que los miembros de la comunidad proceden a compraventas entre ellos, como la venta de la heredad que Hazeme tenía en el valle de

19 RUIZ ASENCIO, José Manuel - Colección documental del archivo de la Catedral de León (7751230), III (986-1031). León: Centro de Estudios e Investigación San Isidoro, 1987, doc. 590 (en adelante= CatLeón III).

${ }^{20}$ SALRACH, José María - "Prácticas judiciales, transformación social y acción política en Cataluña (siglos IX-XIII)”. Hispania. Madrid. LVII/3, 197 (1997), p. 1016. En este sentido también ANDRADE, José Manuel - “Villas regias y asambleas judiciales entre los siglos X y XI: el caso de Larín”. Signum. Pampulha-Belo Horizonte. 12, n. 2 (2011), p. 26.

Medievalista online № 18| Julho - Dezembro 2015 ( ) IEM - Instituto de Estudos Medievais 10 www2.fcsh.unl.pt/iem/medievalista 
Ardón y que Tirso y su mujer Susana compraron en el año 1009, siendo hecha pública esta adquisición in conuentum ecclesie Sancti Cipriani ${ }^{21}$.

Pero además de los documentos que nos permiten una fácil identificación de lugares de reunión para la resolución de conflictos sobre propiedades de la zona objeto de estudio, aparecen algunos otros diplomas que hacen mención a procesos judiciales o partes de ellos, aunque no especifican el lugar exacto donde se trató de resolver el problema. Entre ellos, algunos de peculiares características, como el que hace mención al acuerdo alcanzado en el año 938, tras un litigio que comenzó tres años antes, cuyo proceso se dirimió ante el rey Ramiro II en varias fases con la intervención de varios jueces y de una comisión de fideles que trabajó sobre el terreno tratando de averiguar si la demanda del abad Balderedo, del monasterio de Valdevimbre, contra Gondemaro y sus herederos tenía una base cierta ${ }^{22}$. El documento aporta detalles de la procedencia de Gondemaro, que pertenecía a la colación de San Juan de Vega de Infanzones, así como del proceso judicial, ya sea tanto del problema que originó el conflicto y que se debía a la construcción de unos molinos que los monjes aseguraban que perjudicaban a los suyos, como los nombres de los jueces y obispos que intervinieron en las sesiones, y del trabajo de campo que realizó la comisión encargada de hacer una pesquisa sobre el terreno de los niveles de agua en el curso del río para la verificación o no de los argumentos del abad Balderedo. Lo que no especifica el documento es el lugar de celebración de las vistas ante el monarca y su consejo, aunque sí parece, como ya hemos planteado, que el proceso se debió de producir en varias fases ¿'Se pudo producir en la colación de San Juan en Vega, o en la sede regia leonesa? El documento no arroja datos que puedan confirmar ninguna de estas dos posibilidades -o el que las vistas se produjeran en otro lugar distinto a los dos señalados- en un proceso de tres años de duración, teniendo en cuenta las reclamaciones de los monjes. Un caso parecido se produjo en el año 968, cuando la reina Elvira y sus más altos consejeros dirimieron un conflicto que enfrentó al monasterio de los Santos Justo y Pastor y a Íñigo Garcés por la posesión de unas villas de la zona de $\operatorname{Ardón}^{23}$. En otros casos, la intervención en

\footnotetext{
${ }^{21}$ CatLeón III, doc. 682.

${ }^{22}$ CatLeón I, doc. 128.

${ }^{23}$ CatLeón II, doc. 410. El documento no dice expresamente que este proceso se llevara a cabo en la capital leonesa, pero teniendo en cuenta la importancia de los litigantes y sus reclamaciones, así como los
}

Medievalista online № 18| Julho - Dezembro 2015 @ IEM - Instituto de Estudos Medievais 11 www2.fcsh.unl.pt/iem/medievalista 
algunos de estos pleitos de condes como Munio Fernández, Pelayo Muñiz o Sancha Muñiz, nos encamina al ámbito de los tribunales condales. Así ocurre en un diploma del 994 en el que Cida Aion entregó a Munio Fernández y su mujer Elvira una corte cum kasas et cum cubas et cum lagare, terras, uineas, montes, cessum et regressum, aquis aquarum molinarias discurrentibus, prados, para conmutar la pena de servidumbre a la que pudo ser condenada por haber cometido adulterio ${ }^{24}$. A pesar de que el diploma ofrece bastantes detalles sobre el proceso, no se obtiene de él ninguno en lo que concierne al lugar exacto en el que se desarrolló el pleito. De igual modo sucede con dos documentos en los que intervinieron el matrimonio formado por los condes Pelayo Muñiz y su esposa la condesa Sancha Muñiz. En el primero de ellos, en febrero de 1029, se actuó contra un matrimonio que golpeó a un hombre de los condes y aunque no conocemos el lugar de celebración del juicio, sí sabemos que se desarrolló ante un juez de nombre Salvador que estuvo asistido por un sayón de nombre Sarracino ${ }^{25}$. En el segundo de los casos - unos meses más tarde del mismo año - tampoco el documento ofrece una ubicación exacta del lugar donde se celebró el juicio aunque el documento nos da algunas pistas: se perpetró el asesinato de un hombre de los condes Pelayo Muñiz y doña Sancha en una villa del conde, cuyo nombre no se especifica, aunque sí el lugar de residencia del homicida, que era de Benazolve (lugar cercano a Valdevimbre y Ardón); el diploma también nos indica que los condes metieron en su cárcel al homicida, pero tampoco ubica dónde estaba situada esta cárcel condal ${ }^{26}$. Sabemos que Munio Fernández y su hija, la condesa Sancha Muñiz, poseyeron propiedades en la zona de Valdevimbre, pero en ninguno de los casos mencionados podemos concretar en qué lugar exacto estos condes celebraron sus vistas judiciales ${ }^{27}$. De un posible delito de

intervinientes en el proceso judicial -la reina y su consilium regio- y que se menciona en el diploma que los juramentos se tomaron en las iglesias de San Pedro y San Claudio -las dos tienen advocación en León y la primera fue sede episcopal hasta su traslación a Santa María-, todo podría indicar que efectivamente se produjo en León. Sobre las iglesias de San pedro y San Claudio en León, vid. ESTEPA, Carlos Estructura social de la ciudad de León (Siglos XI-XIII). León: Centro de Estudios e Investigación San Isidoro, 1977, pp. 115-118.

${ }^{24}$ CatLeón III, doc. 561.

${ }^{25}$ CatLeón III, doc. 851.

${ }^{26}$ CatLeón III, doc. 856.

27 Sobre las propiedades de Sancha Muñiz, vid. TORRES SEVILLA, Margarita y GALVÁN FREILE, Fernando - "La condesa Doña Sancha. Una nueva aproximación a su figura”. Medievalismo. Murcia. 5 (1995), pp. 14-16; y TORRES SEVILLA, Margarita - "Munio Fernández y su descendencia. Vida, patrimonio y política familiar de un conde de Astorga”. Astorica. Astorga. 14 (1995), pp. 165-166 y 168170.

Medievalista online № 18| Julho - Dezembro 2015 ๑ IEM - Instituto de Estudos Medievais 12 www2.fcsh.unl.pt/iem/medievalista 
adulterio nos informa un documento, ya rayando la mitad del siglo XI, en el que también intervino la condesa doña Sancha Muñiz. En la primavera del año 1044 un tal Vellite tuvo que entregar a la condesa toda su heredad en Ardón como pago de una fianza a la que se había obligado por una hermana suya que había huido con un hombre casado $^{28}$. El documento tampoco nos dice nada del lugar donde la condesa habría iniciado el proceso, fruto del cual terminó por adquirir las propiedades de Vellite. De un año posterior es otro diploma que nos informa de un litigio en el que se vieron envueltos un tal Vitales y el abad Helyas del monasterio de Valdevimbre, en el que el monasterio reclamó en juicio una tierra a Vitales que éste hubo de devolver al monasterio ${ }^{29}$. Como en anteriores ocasiones, el texto del documento da todo lujo de detalles sobre el proceso, pero nada dice del lugar donde se pudo celebrar éste ${ }^{30}$.

El que se produjera un desplazamiento de los lugares de reunión de la comunidad para la resolución de ciertos conflictos, no tiene por qué ser indicativo de la eliminación al completo de los lugares de reunión de la propia comunidad, ni tampoco esto implica que se desvaneciesen totalmente las formas organizativas en su seno. Durante el siglo $\mathrm{X}$ asistimos, sin duda, a un proceso en el que las sociedades locales se habían ido transformando, adquiriendo mayor complejidad social y también un grado mayor de desigualdad social entre sus propios miembros, a la vez que, progresivamente, la presencia de grupos de poder dominantes se fue haciendo más intensa en la zona de Ardón y Valdevimbre, donde estas comunidades estaban asentadas, y se relacionaron con las elites que habían ido surgiendo dentro de las comunidades ${ }^{31}$. La aparición a

\footnotetext{
${ }^{28}$ RUIZ ASENCIO, José Manuel, Colección documental del archivo de la Catedral de León (775-1230), IV ((1032-1109). León: Centro de Estudios e Investigación San Isidoro, 1987, doc. 1013 (en adelante=CatLeón IV $)$.

${ }^{29}$ CatLeón IV, doc. 1028.

${ }^{30}$ En el año 1082 y, por tanto, ya algo alejado del arco temporal que nos habíamos propuesto para nuestro estudio, se produjo otro litigio sobre propiedades del valle de Ardón entre Fernando Juanes y el monasterio de los Santos Justo y Pastor. El proceso, dice el documento, se celebró ante el obispo de León, don Pelayo, y el merino real, Pelayo Domínguez, por lo que podríamos pensar que se hace referencia a León como lugar de reunión, aunque sea de forma indirecta y no de forma explícita, para la resolución del conflicto sobre la corte que estaba en el valle de Ardón y que era el bien sobre el que se litigaba, vid. CatLeón IV, doc. 1228.

${ }^{31}$ Es interesante la reflexión de C. Wickham a propósito del desarrollo de elites en las comunidades y su papel como grupos intermediarios de poder en el proceso de feudalización, vid. WICKHAM, Chris "Comunidades rurales y señorío débil: el caso del norte de Italia, 1050-1250". in ÁLVAREZ BORGE, Ignacio (coord.) - Comunidades locales y poderes feudales en la Edad Media. Logroño: Universidad de La Rioja, 2001, pp. 412-414.
}

Medievalista online № 18| Julho - Dezembro 2015 ๑ IEM - Instituto de Estudos Medievais 13 www2.fcsh.unl.pt/iem/medievalista 
partir del siglo $\mathrm{X}$ en los diplomas de menciones a boni homines abunda en esta idea de un paulatino cambio del equilibrio social en el seno de las comunidades $^{32}$. Las referencias a éstos como intermediarios en algunos de los litigios que se documentan nos llevan a preguntarnos sobre el lugar que ocupaban en las sociedades locales. La mayor parte de los especialistas plantean, con matices, que estos hombres buenos serían una elite campesina que habrían conseguido acumular un poder económico superior al del resto de los campesinos de la comunidad y que, fruto de esa acumulación de riqueza, estarían en una posición inmejorable para convertirse en los mediadores entre los campesinos y los señores, quienes paulatinamente alcanzaron así mejores condiciones para controlar y dominar a las sociedades locales ${ }^{33}$.

32 C. Estepa plantea que los iudices de las comunidades que aparecen también en algunos diplomas podrían formar parte de esas elites de la comunidad, vid. ESTEPA, Carlos - "Poder y propiedad feudales en el período astur: las mandaciones de los Flainez en la montaña leonesa". in Miscel.làlia en Homenatge al P. Agustí Altisent, Tarragona: Diputació de Tarragona, 1991, p. 305. Sobre la figura de los jueces son interesantes los trabajos de DAVIES, Wendy - "Judges and judging: truth and justice in northern Iberia on the eve of the millennium”. Journal of Medieval History. Southampton. 36:3 (2010), pp. 193-203, y también DAVIES, Wendy - "Summary Justice and Seigneurial Justice in Northern Iberia on the Eve of the Milennium”. The Haskins Society Journal. Woodbridge, Suffolk. 22 (2010), p. 49.

${ }^{33}$ MÍNGUEZ FERNÁNDEZ, José María - "Justicia y poder en el marco de la feudalización de la sociedad leonesa". in La Giustizia nell'alto medioevo (secoli IX-XI). 11-17 aprile 1996. Settimane di Studio del Centro Italiano di Studi sull'alto Medioevo. Spoleto: Centro Italiano di Studi sull'alto Medioevo. XLIV (1997), p. 541. Un planteamiento similar en SALRACH, José María - "Prácticas judiciales, transformación social y acción política en Cataluña (siglos IX-XIII)”. Hispania. Madrid. LVII/3, 197 (1997), p. 1015. La actuación de los boni homines en los litigios como mediadores sociales es resaltada por encima de los demás aspectos por P. Martínez Sopena, que se preocupa también por la representación grupal de los boni homines en los concilios de la comunidad, vid. MARTÍNEZ SOPENA, Pascual - "La justicia en la época asturleonesa: entre el Liber y los mediadores sociales". in Rodríguez, Ana (ed.) - El lugar del campesino. En torno a la obra de Reyna Pastor. Valencia: Universitat de València, 2007, p. 249 y 255-256. C. Wickham defiende que esta alianza entre boni homines y los señores era mucho más efectiva de cara al control de las aldeas y la exigencia de cualquier derecho señorial dentro de éstas que el uso de la violencia o la imposibilidad de poder estar en todas y cada una de las comunidades aldeanas donde los señores poseyeran intereses, vid. WICKHAM, Chris - "Comunidades rurales y señorío débil: el caso del norte de Italia, 1050-1250”. in ÁLVAREZ BORGE, Ignacio (coord.) Comunidades locales y poderes feudales en la Edad Media. Logroño: Universidad de La Rioja, 2001, pp. 412-413. Wendy Davies, en un trabajo que verá la luz próximamente, profundiza en esta figura de los boni homines en la Península Ibérica y deja traslucir sus dudas sobre la dificultad real que existe a la hora de establecer específicamente el estatus social de estos personajes, puesto que en la mayor parte de las ocasiones las referencias a estos hombres buenos en los documentos son muy vagas y no se les puede identificar individualmente, vid. DAVIES, Wendy - Windows on Justice. Record and practice in the courts of northern Iberia at the end of the first millennium, Part II, chapter 6: People and Role Play, (en prensa). Agradezco sinceramente a Wendy Davies el que me haya permitido consultar su trabajo antes de su publicación.

Medievalista online № 18| Julho - Dezembro 2015 ๑ IEM - Instituto de Estudos Medievais 14 www2.fcsh.unl.pt/iem/medievalista 
La actuación de los boni homines como intermediarios reconocidos en los conflictos fue un hecho generalizado en la Península Ibérica ${ }^{34}$. En la zona de Valdevimbre y Ardón encontramos varios diplomas en los que estos hombres buenos son mencionados en los siglos X y XI. Sus apariciones estuvieron o bien relacionadas con su labor de mediación en algún tipo de conflicto, o bien como personajes de prestigio dentro de la comunidad cuya actuación o presencia pretendía añadir valor y garantía al acto jurídico en sí mismo. Ese prestigio que ostentaban estos hombres buenos en el seno de sus comunidades locales es perceptible en dos donaciones del año 983 y dos ventas, una del año 986 y otra del año 991, todas ellas al monasterio de los Santos Justo y Pastor de Ardón, donde encontramos en los escatocolos de los documentos que se consignó la presencia de bonorum hominum en la firma de estos actos jurídicos ${ }^{35}$. Pero quizá un mejor ejemplo de su especial significancia fue la actuación de Todrigo Garcéaz y Salamón Facámez como ejecutores del testamento de otro miembro de su comunidad, Pelayo Cítiz. Estos dos personajes fueron llamados en su calidad de homines bonos por Lebsenda, la esposa de Pelayo, y sus hijos para que ejecutaran su testamento entregando la villa de Fuentes de San Adrián a Orfilo Salvadóriz en $1049^{36}$.

De entre los diplomas del siglo $\mathrm{X}$ hay uno - ya mencionado anteriormente- que se refiere a la entrega de bienes que Godesteo y Alvito realizaron en pago de una multa en el año 999 al monasterio de Ardón por la tala de árboles, propiedad del monasterio, que llevaron a cabo. Este documento, en lo que se refiere a la presencia de hombres buenos en este conflicto, podría estar a caballo entre las dos categorías que hemos mencionado,

\footnotetext{
${ }^{34}$ Conocemos ejemplos de la actuación de los boni homines desde Portugal hasta los condados catalanes, vid. DAVIES, Wendy - "Summary Justice and Seigneurial Justice in Northern Iberia on the Eve of the Millennium”, The Haskins Society Journal, vol. 22 (2010). Studies in Medieval History, pp. 43-44; SALRACH, José María - "Prácticas judiciales, transformación social y acción política en Cataluña (siglos IX-XIII)”. Hispania. Madrid. LVII/3, 197 (1997), p. 1011; MARTÍNEZ SOPENA, Pascual - "La justicia en la época asturleonesa: entre el Liber y los mediadores sociales”. in Rodríguez, Ana (ed.) - El lugar del campesino. En torno a la obra de Reyna Pastor. Valencia: Universitat de València, 2007, pp. 248-249. Pero su presencia documental va más allá de las fronteras peninsulares, encontrando a estos personajes en Italia o el Imperio Franco, entre otros lugares, vid. DAVIES, Wendy - Windows on Justice. Record and practice in the courts of northern Iberia at the end of the first millennium, Part II, chapter 6, (en prensa).

${ }^{35}$ Las fórmulas empleadas fueron: "in collegium fratrum Sanctorum Iusti et Pastoris, ubi sunt filii multorum bonorum hominum; in concilio Sancte Eolalie, ubi fuerunt multorum bonorum hominum; in uentionum ecclesie Sancte Columbe ubi fuerunt filii multorum bonorum hominum o in collegium Sanctorum lusti et Pastoris ubi fuerunt multorum filii bonorum hominum”, vid. CatLeón II, doc. 490 y doc. 492, y CatLeón III, doc. 513 y doc. 547.

${ }^{36}$ CatLeón IV, doc. 1068.
}

Medievalista online № 18| Julho - Dezembro 2015 ๑ IEM - Instituto de Estudos Medievais 15 www2.fcsh.unl.pt/iem/medievalista 
pues en el mismo no se menciona la labor de mediación de éstos en el litigio que tuvo lugar por la acción de Godesteo y Alvito, pero sí que los encontramos presentes en la firma del documento de acuerdo por el que los dos hombres con sus mujeres se comprometían a la entrega de unas tierras y un soto en compensación por su "fechoría”37. Cabría pensar que estos hombres buenos habrían mediado entre el monasterio y Godesteo y Alvito para que éstos pudieran llegar a un acuerdo con el cenobio para hacer frente a la pena impuesta en el proceso judicial, que no es mencionada en el acuerdo final.

De los diplomas conservados, como ya hemos mencionado, los que tienen que ver directamente con litigios son los que nos dan una idea más clara de la labor negociadora de estos personajes para que algunos miembros de la comunidad que estaban siendo juzgados por algún delito cometido, alcanzaran alguna condición más “ventajosa” frente a la pena o multa que se les habría impuesto de no haber mediado ellos en el proceso encabezado por algún magnate o algún representante del poder central. Es muy interesante un conocido documento de inicios del siglo XI en el que un matrimonio, Tidón y Massoria, fue condenado al pago de una multa de 280 sueldos de plata al conde Pelayo Muñiz y su esposa la condesa Sancha por haber propinado una paliza a un hombre, de nombre Cid, que estaba robando en su casa. Al no tener esta suma de dinero para hacer frente a la condena por haberse arrogado una facultad que sólo les correspondía a los condes, Tidon y Massoria hablaron con los omines bonos -es de suponer que de la villa a la que ellos pertenecían- que intercedieron ante los condes para llegar a un acuerdo en el que los campesinos entregarían una villa en Valdevimbre en compensación al pago de los 280 sueldos de plata ${ }^{38}$. Unos meses más tarde, estos mismos condes volvieron a recibir la entrega de cuatro aranzadas de viña en Valdevimbre y la mitad de los bienes de Doval Héctaz como pago por haber asesinado a un hombre de los citados condes. El acuerdo de este pago por el homicidio fue negociado por los hombres buenos de la villa de Doval, que mediaron por él ante Pelayo

\footnotetext{
37 "Qui preses hic fuerunt in conuentu ecclesia Sancti Iusti et Pastoris multorum filiorum bonorum hominum”, vid. CatLeón III, doc. 590.

${ }^{38}$ CatLeón III, doc. 851.
}

Medievalista online № 18| Julho - Dezembro 2015 ๑ IEM - Instituto de Estudos Medievais 16 www2.fcsh.unl.pt/iem/medievalista 
Muñiz que le tenía encarcelado en su prisión por el crimen y no tenía dinero con el que pagar por el delito cometido ${ }^{39}$.

Como hemos visto, los documentos que poseemos para la zona de Valdevimbre y Ardón donde aparecen mencionados estos boni homines en alguna de las actividades de mediación o como elementos de prestigio cuya presencia ayudaba a sancionar públicamente el acto jurídico en el que tomaban parte, no son demasiado numerosos si los comparamos con aquéllos otros que atestiguan la presencia de presbíteros, como tendremos ocasión de ver ${ }^{40}$. En casi todos ellos -siete de los ocho- se mantiene la utilización de fórmulas estándar y, por tanto, genéricas para referirse a estos hombres buenos, excepto en uno en el que sí es posible identificar a dos de ellos -Todrigo Garcéaz y Salamon Facámez- que actuaron como ejecutores testamentarios de la última voluntad de Pelayo Cítiz en 1049. En el rastreo que hemos llevado a cabo en la documentación leonesa, no ha sido posible encontrar a estos dos hombres buenos mencionados en otros documentos en los que pudiésemos comprobar el volumen de propiedades que estos dos individuos pudieron poseer, de manera que a partir de este dato no es posible inferir si eran propietarios acaudalados o no en la zona. Esta carencia de datos más específicos sobre los boni homines dificulta la posibilidad real de conocer cuál fue el origen de la posición "privilegiada” que pudieron ostentar en el seno de sus comunidades. Sin duda, el que fueran elegidos dentro de ellas para desempeñar una determinada función como negociadores ante otras instancias superiores de poder, o como ejecutores testamentarios, pone de relieve que el estatus que tenían estos hombres buenos les habilita para ejercer una serie de funciones que otros no parecen haber estado capacitados para llevar a cabo. La cuestión a resolver es, por tanto, de dónde surgió el

\footnotetext{
${ }^{39}$ CatLeón III, doc. 856.

${ }^{40}$ Con todo, habría que tener en cuenta también otro tipo de posibilidades en lo que se refiere al escaso volumen de referencias de estos hombres buenos en los documentos del siglo X, ya que como Wendy Davies argumenta cabría la posibilidad de que estuviéramos ante una falta de datos, de forma general para todo el norte peninsular, provocada no tanto porque estos boni homines no existieran hasta que aparecen tardíamente a finales del siglo X y ya más reiteradamente en el siglo XI, sino porque todo se debiera a una cuestión estilística en cuanto a la redacción de los diplomas por parte de los escribas, siendo a finales del siglo X cuando se produjo un cambio en los hábitos de escritura que llevó a reflejar a esos hombres buenos en los documentos, aunque en la práctica ya habrían estado actuando con anterioridad como simples testigos en los escatocolos de los mismos, lo que les habría hecho pasar desapercibidos y sin ninguna relevancia social hasta ese momento, vid. DAVIES, Wendy - Windows on Justice. Record and practice in the courts of northern Iberia at the end of the first millennium, Part II, chapter 6: People and Role Play, (en prensa).
}

Medievalista online № 18| Julho - Dezembro 2015 ๑ IEM - Instituto de Estudos Medievais 17 www2.fcsh.unl.pt/iem/medievalista 
prestigio social que tenían estos individuos para llevar a cabo las actuaciones de mediación. ¿¿Fue el ejercicio de esas funciones específicas el que ayudó a incrementar su prestigio, o el hecho de que poseyeran ya ese prestigio era lo que les habilitaba para llevar a cabo esas funciones en determinados momentos? No creo que sean excluyentes ninguna de las dos posibilidades $\mathrm{y}$, en todo caso, a falta de más datos para poder responder de una forma satisfactoria estos interrogantes, lo que parece claro es que actuaciones como las que hemos visto en los procesos abiertos contra Tidon y Massoria o contra Doval Héctaz, nos revelan que existía algún grado de desigualdad social palpable en estas comunidades locales.

Al hablar de desigualdad en el seno de la comunidad local, no podemos dejar de referirnos a los presbíteros que aparecen de forma reiterada en la documentación. Estos presbíteros, generalmente, formaban parte de las comunidades locales y como consecuencia del desempeño de ciertas funciones -como la de escribas- en el seno de éstas -entre ellas cabrían también las religiosas en algunos casos- consiguieron una posición destacada dentro de las mismas, a lo que se sumó la acumulación de bienes patrimoniales $^{41}$. Las dos -aumento de estatus por el ejercicio de ciertas funciones y acumulación de patrimonio- fueron unidas y una fue consecuencia de la otra, provocando que estos presbíteros se convirtieran en una elite dentro de la comunidad, lo que les situaba en una posición destacada para relacionarse con el poder central u otros poderes vinculados a ese poder central, como las aristocracias laica y eclesiástica, generando a su vez relaciones clientelares ${ }^{42}$.

Los diplomas referidos a la zona de Valdevimbre y Ardón recogen menciones a estos clérigos locales desde los inicios del siglo $X^{43}$. En el año 918 aparecen firmando dos

\footnotetext{
${ }^{41}$ C. Estepa reconoce su papel preferente en el seno de la comunidad al margen del desempeño o no de la función religiosa, vid. ESTEPA, Carlos - "Poder y propiedad feudales en el período astur: las mandaciones de los Flainez en la montaña leonesa”. in Miscel.làlia en Homenatge al P. Agustí Altisent, Tarragona: Diputació de Tarragona, 1991, pp. 310-311.

${ }^{42}$ I. Martín explica bien la interconexión entre desempeño de funciones específicas y la acumulación de bienes en el proceso de cambios en las estructuras sociales de las sociedades locales refiriéndose a los presbíteros de la zona del alto Ebro y del occidente zamorano, vid. MARTÍN VISO, Iñaki - Poblamiento y estructuras sociales en el norte de la Península Ibérica, siglos VI-XIII. Salamanca: Ediciones Universidad de Salamanca, 2000, pp. 192-193 y 196-197.

${ }^{43}$ Las menciones documentales de los presbíteros se producen también en otras zonas del espacio leonés, vid. ESTEPA, Carlos - "Poder y propiedad feudales en el período astur: las mandaciones de los Flainez en la montaña leonesa”. in Miscel.làlia en Homenatge al P. Agustí Altisent, Tarragona: Diputació de
}

Medievalista online № 18| Julho - Dezembro 2015 ๑ IEM - Instituto de Estudos Medievais 18 www2.fcsh.unl.pt/iem/medievalista 
presbíteros en un documento de Ordoño II relacionado directamente con la zona de Valdevimbre y con su monasterio. Los dos presbíteros, Ermegiro y Anfíloco, están perfectamente identificados en el documento, aunque Ermegiro es descrito con mayor exactitud como primicerio del monasterio de Valdevimbre, mientras que Anfíloco lo es tan sólo como notario, sin mayores detalles ${ }^{44}$. A partir de esta fecha, las menciones documentales de este tipo de individuos son múltiples. La documentación con la que hemos trabajado nos permite elaborar dos listados de presbíteros. Por un lado, se registra la actividad de más de una veintena de presbíteros diferentes realizando negocios jurídicos y relacionándose con el poder central, con otros miembros de la comunidad o con monasterios asentados en la zona. Pero además de éstos, que aparecen en los documentos como actores de los negocios jurídicos relacionados con propiedades de la zona objeto de estudio, los diplomas nos muestran también a otros que actuaban como confirmantes o escribas de los documentos y de los que, más allá de su nombre, no tenemos más información de su actividad en estos espacios ${ }^{45}$.

\section{TABLA PRESBÍTEROS 1}

\begin{tabular}{|c|c|c|l|}
\hline FECHA & DoCUMENTO & NOMBRES & \multicolumn{1}{|c|}{ RELACIONADO CON... } \\
\hline 918.01.08 & CatLeón 45 & $\begin{array}{c}\text { Ermegiro confirma en un } \\
\text { documento como primicerio } \\
\text { del monasterio de Santiago de } \\
\text { Valdevimbre }\end{array}$ & $\begin{array}{l}\text { Monasterio de Santiago de } \\
\text { Valdevimbre }\end{array}$ \\
\hline 932.04 .22 & CatLeón 93 & Benedicto & $\begin{array}{l}\text { Monasterio de los Santos Justo y } \\
\text { Pastor. }\end{array}$ \\
\hline 937.06 .19 & CatLeón 115 & Vermudo y Gudino (o & $\begin{array}{l}\text { Monasterio de Santa María y } \\
\text { Santiago de Valdevimbre }\end{array}$ \\
\hline 937.09 .22 & CatLeón 119 & Speraindeo & Monasterio de Santos Justo y Pastor \\
\hline 941.07 .16 & CatLeón 144 & Nemorelli & Monasterio de Valdevimbre \\
\hline 943.08 .27 & CatLeón 176 & Berulfo & Monasterio de Santos Justo y Pastor \\
\hline 944.09 .24 & CatLeón 186 & Berulfo & Monasterio de Santos Justo y Pastor \\
\hline 946.05 .07 & CatLeón 192 & Berulfo & Monasterio de Santos Justo y Pastor \\
\hline
\end{tabular}

Tarragona, 1991, p. 307. Para la zona castellana, vid. ÁLVAREZ BORGE, Ignacio - Poder y relaciones sociales en Castilla en la Edad Media. Los territorios entre el Arlanzón y el Duero en los siglos X al XIV. Salamanca: Junta de Castilla y León, 1996, p. 31.

${ }^{44}$ CatLeón I, doc. 45.

${ }^{45}$ Se han recogido en esta segunda tabla no sólo los nombres de aquéllos que figuraban en los diplomas como presbíteros, sino también los que eran calificados como "confessor". Sobre la diversidad de presbíteros, DAVIES, Wendy - "Local priests in northern Iberia”. in PATZOLD, Steffen y VAN RHIJN, Carine (eds.) - Men in the Middle. Local Priests in Early Medieval Europe. Berlin: De Gruyter, (en prensa). Quiero agradecer a Wendy Davies su amabilidad por permitirme conocer de primera mano este trabajo antes de su publicación.

Medievalista online № 18| Julho - Dezembro 2015 ๑ IEM - Instituto de Estudos Medievais 19 www2.fcsh.unl.pt/iem/medievalista 
Lugares de reunión, boni homines y presbiteros en Valdevimbre y Ardón en la Alta Edad Media • Fernando Luis Corral

\begin{tabular}{|c|c|c|c|}
\hline & & $\begin{array}{l}\text { Flaino, testigo que aporta } \\
\text { Berulfo en el litigio }\end{array}$ & \\
\hline 951.01 .01 & CatLeón 231 & Sendramon & Monasterio de Valdevimbre \\
\hline 954.10 .20 & CatLeón 278 & $\begin{array}{c}\text { Julián y (su primo-hermano) } \\
\text { Movía }\end{array}$ & Monasterio de Santos Justo y Pastor \\
\hline 954.10 .20 & CatLeón 279 & Julián & Monasterio de Santos Justo y Pastor \\
\hline 954.12 .03 & CatLeón 283 & Rapinato & Monasterio de Santos Justo y Pastor \\
\hline 956.08 .30 & CatLeón 298 & Berulfo & Monasterio de Santos Justo y Pastor \\
\hline 958.05 .28 & CatLeón 306 & Oveco & Monasterio de Santos Justo y Pastor \\
\hline 959.01 .16 & CatLeón 312 & $\begin{array}{c}\text { Berulfo y Hanni como } \\
\text { integrantes de un concilio que } \\
\text { juzgó una causa en León }\end{array}$ & Monasterio de Santos Justo y Pastor \\
\hline 960.04 .29 & CatLeón 327 & Habze & Monasterio de Santos Justo y Pastor \\
\hline 968.10 .04 & CatLeón 410 & Berulfo & Monasterio de Santos Justo y Pastor \\
\hline 972.02 .01 & CatLeón 418 & Abolbalite & $\begin{array}{l}\text { Venta al presbítero Abolbalite de una } \\
\text { viña }\end{array}$ \\
\hline 974.07 .21 & CatLeón 432 & $\begin{array}{l}\text { Speraindeo, Iuliano, que era } \\
\text { qui tunc est palacii domus } \\
\text { sequonomus, y Sendino } \\
\text { Puricelliz (ahora obispo } \\
\text { Sisnando de León) } \\
\end{array}$ & Monasterio de Santos Justo y Pastor \\
\hline 983.05 .01 & CatLeón 490 & Arcisclo & Monasterio de Santos Justo y Pastor \\
\hline 1002.03 .23 & CatLeón 619 & Esteban & Monasterio de Santos Justo y Pastor \\
\hline 1002.06 .06 & CatLeón 620 & Sesemiro & Monasterio de Santos Justo y Pastor \\
\hline 1009.12.13 & CatLeón 683 & Domingo & Monasterio de Valdevimbre \\
\hline 1030.04 .25 & CatLeón 865 & Iohannes y Domingo & $\begin{array}{l}\text { Monasterio de San Juan Bautista y de } \\
\text { Santa María }\end{array}$ \\
\hline 1033.07.08 & CatLeón 918 & Fronimio & Monasterio de Santos Justo y Pastor \\
\hline 1036.03.18 & CatLeón 945 & Esteban & Monasterio de Santos Justo y Pastor \\
\hline 1037.02 .24 & CatLeón 949 & Bonomen y Salvador & Monasterio de Santos Justo y Pastor \\
\hline 1049.01.31 & CatLeón 1062 & Mondrico & $\begin{array}{l}\text { Citi, Subero y Vita Petrici venden al } \\
\text { presbítero Mondrico unas viñas }\end{array}$ \\
\hline 1049.07.15 & CatLeón 1066 & Micahel & $\begin{array}{l}\text { Obispo Cipriano y al monasterio de } \\
\text { los Santos Justo y Pastor }\end{array}$ \\
\hline 1058.02.20 & CatLeón 1112 & Montrigo & Monasterio de San Salvador \\
\hline
\end{tabular}

TABLA PRESBÍTEROS 2

\begin{tabular}{|c|c|c|}
\hline FECHA & DOCUMENTO & REFERENCIA DE NOMBRES EN LOS DIPLOMAS \\
\hline 918.01 .18 & CatLeón 45 & Amphilocius presbiter notarius. \\
\hline 918.04 .24 & CatLeón 47 & Rodericus presbiter conf. \\
& & Daniel presbiter conf. \\
& & Aspidivs presbiter notuit (signum). \\
\hline 932.04 .22 & CatLeón 93 & Audericus presbiter ts. \\
\hline 937.09 .22 & CatLeón 119 & Dulcidius presbiter conf. \\
& & Ouecco presbiter conf. \\
\hline 937.12 .19 & CatLeón 123 & Berulfus presbiter conf. \\
& & Berulfus presbiter conf. \\
& & Fredenandus presbiter conf. \\
& & Balderedus presbiter conf. \\
& & Leouegildus confessor conf. (signum). \\
& & Iohannes presbiter conf. \\
\hline
\end{tabular}

Medievalista online № $18 \mid$ Julho - Dezembro 2015 @ IEM - Instituto de Estudos Medievais 20 www2.fcsh.unl.pt/iem/medievalista 


\begin{tabular}{|c|c|c|}
\hline & & $\begin{array}{c}\text { Elias confessor conf. } \\
\text { Dominicus confessor conf. }\end{array}$ \\
\hline 941.07.16 & CatLeón 144 & Aspidius presbiter \\
\hline 943.08 .27 & CatLeón 176 & $\begin{array}{l}\text { Genesius presbiter conf. } \\
\text { Saluti presbiter conf. } \\
\text { Abraham presbiter conf. } \\
\text { Hanni presbiter conf. } \\
\text { Cesanus presbiter conf. } \\
\text { Vnileo presbiter conf. } \\
\text { Citaio presbiter conf. } \\
\text { Velasco presbiter conf. }\end{array}$ \\
\hline 944.09 .24 & CatLeón 186 & $\begin{array}{l}\text { Andreas presbiter ts. } \\
\text { Kacem presbiter ts. } \\
\text { Adulfus presbiter ts. } \\
\text { Adefonsus presbiter ts. } \\
\text { Mantelli presbiter ts. } \\
\text { Iohannes presbiter ts. } \\
\text { Froila presbiter ts. }\end{array}$ \\
\hline 946.05 .07 & CatLeón 192 & $\begin{array}{l}\text { Hacem presbiter. } \\
\text { Teouigildus presbiter. } \\
\text { Adrias presbiter. } \\
\text { Mantelli presbiter. } \\
\text { Alamiro presbiter. } \\
\text { Mutarraf presbiter. } \\
\text { Celso presbiter. } \\
\text { Micael presbiter. } \\
\text { Abonazar presbiter. } \\
\text { Titon presbiter. } \\
\text { Gondemarus presbiter. }\end{array}$ \\
\hline 950.08 .23 & CatLeón 227 & $\begin{array}{l}\text { Bonus confessor testes (signum). } \\
\text { Elias confessor ts. (signum). } \\
\text { Aluinus ts. (signum). } \\
\text { Salomon confessor ts. (signum). } \\
\text { Fortes confessor ts. (signum). } \\
\text { Uimara presbiter ts. (signum). }\end{array}$ \\
\hline 952.02 .08 & CatLeón 243 & Baroncellus presbiter notuit (signum). \\
\hline 952.02 .24 & CatLeón 244 & $\begin{array}{l}\text { Saluatus confessor conf. } \\
\text { Vimara presbiter conf. }\end{array}$ \\
\hline 952.02 .24 & CatLeón 245 & Iustus presbiter notuit. \\
\hline 952.02 .29 & CatLeón 247 & $\begin{array}{l}\text { Ciprianus presbiter conf. } \\
\text { Fafila presbiter ts. }\end{array}$ \\
\hline 952.03.21 & CatLeón 249 & Baroncellus presbiter scripsit (signum). \\
\hline 952.03 .23 & CatLeón 250 & Baroncellus presbiter notuit (signum). \\
\hline 952.06 .22 & CatLeón 254 & $\begin{array}{c}\text { Baronzellus presbiter conf. } \\
\text { Nembrel presbiter de Auctarios ts. }\end{array}$ \\
\hline 954.02 .07 & CatLeón 266 & Frola presbiter notvit (signum). \\
\hline 954.03 .23 & CatLeón 267 & Salomon presbiter ts. \\
\hline 954.06 .22 & CatLeón 271 & $\begin{array}{c}\text { Ordonius presbiter ts. } \\
\text { Froila presbiter notuit (signum). }\end{array}$ \\
\hline 954.07 .23 & CatLeón 272 & Froia presbiter scripsit (signum). \\
\hline 954.10 .20 & CatLeón 278 & $\begin{array}{l}\text { Rapinatus presbiter conf. } \\
\text { Adulfus presbiter conf. } \\
\text { Ivstus presbiter notuit (signum). }\end{array}$ \\
\hline 954.10.20 & CatLeón 279 & $\begin{array}{c}\text { Adulfus presbiter conf. } \\
\text { Rapinatus presbiter conf. } \\
\text { Ivstvs presbiter notvit (signum). }\end{array}$ \\
\hline 955.04 .03 & CatLeón 285 & Baroncellus presbiter scripsit. \\
\hline 955.08 .23 & CatLeón 291 & Meneze presbiter ts. \\
\hline
\end{tabular}

Medievalista online № 18| Julho - Dezembro 2015 ๑ IEM - Instituto de Estudos Medievais 21 


\begin{tabular}{|c|c|c|}
\hline & & Dominicus presbiter notvit (signum). \\
\hline 955.10 .28 & CatLeón 292 & Dominicvs presbiter notvit. \\
\hline 956.01 .30 & CatLeón 294 & Dominicus presbiter ts. \\
\hline 956.08 .30 & CatLeón 298 & $\begin{array}{l}\text { Melic presbiter conf. } \\
\text { Hanni presbiter conf. } \\
\text { Abraam presbiter conf. } \\
\text { Scipius presbiter conf. } \\
\text { Dulquitus presbiter conf. } \\
\text { Iohannes presbiter conf. } \\
\text { Sisebutus presbiter conf. }\end{array}$ \\
\hline 956.12 .11 & CatLeón 303 & Fofinus presbiter notuit. \\
\hline 959.01 .16 & CatLeón 312 & $\begin{array}{c}\text { Stephano presbiter } \\
\text { Seruodeo presbiter conf. }\end{array}$ \\
\hline 959.01 .24 & CatLeón 313 & $\begin{array}{l}\text { Iulianus presbiter. } \\
\text { Mauiia presbiter ts. }\end{array}$ \\
\hline 960.11 .22 & CatLeón 332 & Ferrolius presbiter conf. \\
\hline 961.01 .24 & CatLeón 336 & Baroncellus presbiter notuit. \\
\hline 961.04 .01 & CatLeón 338 & Baroncellus presbiter scripsit (signum). \\
\hline 961.05 .23 & CatLeón 342 & $\begin{array}{c}\text { Salomon presbiter hic pro teste. } \\
\text { Baroncellus confessor indignus orate pro me ad Christum (signum). }\end{array}$ \\
\hline 968.10 .04 & CatLeón 410 & Zuleyman presbiter. \\
\hline 969.02 .19 & CatLeón 411 & $\begin{array}{l}\text { Froila presbiter conf. } \\
\text { Zvleiman presbiter. } \\
\text { Sumla presbiter. }\end{array}$ \\
\hline $\begin{array}{c}\text { [974- } \\
983] .08 .06\end{array}$ & CatLeón 491 & Maurilio presbiter preses fuit. \\
\hline 974.07 .21 & CatLeón 432 & $\begin{array}{l}\text { Froila presbiter conf. } \\
\text { Dolkit presbiter conf. } \\
\text { Kazem presbiter conf. } \\
\text { Mercatarius presbiter notvit (signum). }\end{array}$ \\
\hline 974.07 .21 & CatLeón 433 & Mercatarius presbiter conf. \\
\hline 980.10 .23 & CatLeón 479 & $\begin{array}{c}\text { Pelagius, presbiter de Domnos Sanctos, conf. } \\
\text { Valerivs presbiter et peccator conf. } \\
\text { Valiti presbiter et iudex conf. } \\
\text { Monivs presbiter notuit (signum). } \\
\text {--------------- } \\
\text { Aurelius confessor conf. } \\
\text { Valerius, presbiter et confessor, conf. } \\
\text { Munniu presbiter et notarius notuit (signum). }\end{array}$ \\
\hline 981.05 .28 & CatLeón 483 & $\begin{array}{c}\text { Gundisaluus presbiter conf. } \\
\text { Nunus presbiter conf. } \\
\text { Marchus presbiter conf. }\end{array}$ \\
\hline 983 & CatLeón 493 & Ennego presbiter notvit (signum). \\
\hline 996.06 .13 & CatLeón 573 & Donadeo presbiter scripsit (monogramma). \\
\hline 1002.03 .23 & CatLeón 619 & $\begin{array}{c}\text { Denius presbiter hic conf. } \\
\text { Stephanus presbiter hic conf. } \\
\text { Iulianus presbiter notuit (monogramma). }\end{array}$ \\
\hline 1009.07.31 & CatLeón 681 & $\begin{array}{c}\text { Gaundila presbiter conf. } \\
\text { Seueranus presbiter notuit (signum) }\end{array}$ \\
\hline 1009.12 .01 & CatLeón 682 & Petrus presbiter scripsit. \\
\hline 1011.09 .28 & CatLeón 701 & Iusto Sarraziniz presbiter notuit (monogramma). \\
\hline 1014.03 .27 & CatLeón 725 & Ordonius presbiter notuit (monogramma). \\
\hline 1017.02 .28 & CatLeón 747 & $\begin{array}{l}\text { Seruandus presbiter conf. } \\
\text { Felice presbiter conf. } \\
\text { Salamon presbiter conf. } \\
\text { Ordonius presbiter conf. } \\
\text { Iohannes presbiter conf. } \\
\text { Fortes presbiter conf. }\end{array}$ \\
\hline
\end{tabular}




\begin{tabular}{|c|c|c|}
\hline & & $\begin{array}{c}\text { Menendus presbiter conf. } \\
\text { Saluator presbiter conf. } \\
\text { Dominicus presbiter conf. } \\
\text { Salamon presbiter conf. } \\
\text { Martinus presbiter conf. } \\
\text { Fulgencius presbiter et notarivs conf. (signum). }\end{array}$ \\
\hline 1021.05 .15 & CatLeón 776 & $\begin{array}{l}\text { Fulgentius presbiter conf. } \\
\text { Iohannes presbiter conf. } \\
\text { Sauaricus presbiter conf. }\end{array}$ \\
\hline 1022.12 .13 & CatLeón 796 & Claudio presbiter scripsit. \\
\hline 1029.02 .25 & CatLeón 851 & Sentando presbiter notuit (signum). \\
\hline 1030.04 .25 & CatLeón 865 & $\begin{array}{c}\text { Sampirus presbiter conf. } \\
\text { Petras presbiter conf. } \\
\text { Gudesteus presbiter notuit (monogramma). }\end{array}$ \\
\hline 1030.07 .09 & CatLeón 876 & Ueremudo presbiter. \\
\hline 1030.07 .09 & CatLeón 877 & Viui presbiter notuit (monogramma). \\
\hline 1033.07 .08 & CatLeón 918 & $\begin{array}{c}\text { Sampirus presbiter conf. } \\
\text { Viui presbiter notuit (signum). }\end{array}$ \\
\hline 1036.03 .21 & CatLeón 946 & $\begin{array}{l}\text { Petras presbiter conf. } \\
\text { Exipius presbiter conf. } \\
\text { Todesindus presbiter conf. } \\
\text { Viui presbiter notvit (signum) }\end{array}$ \\
\hline 1037.02 .24 & CatLeón 949 & $\begin{array}{l}\text { Olitus presbiter confirmat (signum). } \\
\text { Steuanus presbiter cf. (signum). } \\
\text { Monio presbiter cf. (signum). } \\
\text { Iustus presbiter titulauit. }\end{array}$ \\
\hline 1037.02.24 & CatLeón 950 & $\begin{array}{c}\text { Olitus presbiter conf. } \\
\text { Ivstvs presbiter notuit (monogramma). }\end{array}$ \\
\hline 1037.10 .15 & CatLeón 958 & $\begin{array}{c}\text { Facundus presbiter. } \\
\text { Michael presbiter. } \\
\text { Gondisaluus presbiter conf. } \\
\text { Lazarus presbiter conf. } \\
\text { Ueremudo (signum) presbiter notuit (monogramma). }\end{array}$ \\
\hline 1038.08.31 & CatLeón 970 & $\begin{array}{l}\text { Vigila presbiter conf. } \\
\text { Viui presbiter conf. } \\
\text { Citi presbiter conf. } \\
\text { Todesindus presbiter conf. }\end{array}$ \\
\hline 1045.07 .10 & CatLeón 1028 & $\begin{array}{c}\text { Saluator presbiter confirmans (signum). } \\
\text { Gonsaluo presbiter confirmans (signum). } \\
\text { Dominico presbiter confirmans (signum). } \\
\text { Speraindeo presbiter confirmans (signum). } \\
\text { Cipriano presbiter confirmans (signum). } \\
\text { Amor presbiter confirmans. } \\
\text { Unigillo presbiter scripsit (monogramma: Vnigilivs). }\end{array}$ \\
\hline 1047.07 .05 & CatLeón 1045 & $\begin{array}{c}\text { Gontin presbiter conf. (signum). } \\
\text { Dominicus presbiter notuit (signum). }\end{array}$ \\
\hline 1049.01.31 & CatLeón 1062 & Armentero presbiter notui (signum). \\
\hline 1049.07.15 & CatLeón 1066 & $\begin{array}{l}\text { Bondrigo presbiter conf. (signum). } \\
\text { Martinvs presbiter notuit (signum). }\end{array}$ \\
\hline 1049.09.19 & CatLeón 1068 & Kirita presbiter notuit (signum). \\
\hline 1058.02 .20 & CatLeón 1112 & $\begin{array}{l}\text { Garcia presbiter conf. } \\
\text { Dominicus presbiter conf. } \\
\text { Fortes presbiter conf. } \\
\text { Sebastianus presbiter conf. } \\
\text { Iohannes presbiter conf. }\end{array}$ \\
\hline 1063.01 .25 & CatLeón 1125 & $\begin{array}{c}\text { Mondrico presbiter. } \\
\text { Armentero presbiter scripsit (signum). }\end{array}$ \\
\hline
\end{tabular}


Como se observa en las referencias de estos dos cuadros, no todos los presbíteros fueron iguales en las funciones que realizaron, ni ostentaron un mismo estatus dentro y fuera de su comunidad ${ }^{46}$. De hecho, un repaso somero a la lista de los presbíteros mencionados en los diplomas de la zona de Valdevimbre y Ardón nos revela que hay diferencias llamativas entre algunos de ellos. Del primer grupo destacan algunos como Sendino Puricéliz, que llegó a ser obispo legionense, o los presbíteros Berulfo y Speraindeo, que aparecen reiteradamente en los documentos conectados al monasterio de los Santos Justo y Pastor o la catedral de León. A éstos les vemos participando en litigios y adquiriendo, mediante compras y donaciones, bienes para el citado monasterio ${ }^{47}$. Estos bienes, en su mayoría, procedían de miembros de la comunidad. Se podría decir de estos tres clérigos mencionados que habían "ascendido” socialmente lo suficiente como para abandonar su posición de elite de la comunidad y convertirse en representantes de la aristocracia eclesiástica.

Por debajo de la posición social alcanzada por estos individuos, habría un grupo también numeroso de presbíteros que continuó formando parte de esa elite de su comunidad. Éstos poseían un patrimonio fundiario que vendieron o donaron con otros familiares a algunos de los monasterios de la zona o adquirieron más bienes pertenecientes a otros miembros de la comunidad. De este grupo conocemos al presbítero Benedicto que, junto a su madre, donó bienes al monasterio de los Santos Justo y Pastor; o a los presbíteros Vermudo y Gudino que, juntos, entregaban sus bienes al monasterio de Santiago de Valdevimbre ${ }^{48}$. Aparecen también como transmisores de patrimonio hacia sus familiares, como nos relata un diploma del año 960 donde Aeiza y su mujer vendieron al monasterio de los Santos Justo y Pastor la cuarta parte de un

\footnotetext{
${ }^{46} \mathrm{~W}$. Davies ha realizado recientemente un estudio donde profundiza en estos aspectos, vid. DAVIES, Wendy - "Local priests in northern Iberia". in PATZOLD, Steffen y VAN RHIJN, Carine (eds.) - Men in the Middle. Local Priests in Early Medieval Europe. Berlin: De Gruyter, (en prensa).

${ }^{47}$ CatLeón I, doc. 119, doc. 176, doc. 186, doc. 192, CatLeón II, doc. 298, doc. 312, doc. 410 y doc. 432. Destacable es también Vincemalo, que aparece en un documento del año 937, aunque su labor más reconocida y donde aparece como presbítero se desarrolló más al este, vid. LUIS CORRAL, Fernando Villavicencio en la Edad Media. Propiedad y jurisdicción en los valles del Cea y del Valderaduey. Valladolid: Diputación de Valladolid, 2003, pp. 105-113.

${ }^{48}$ CatLeón I, doc. 93, doc. 115
}

Medievalista online $N^{\circ} 18$ | Julho - Dezembro 2015 ๑ IEM - Instituto de Estudos Medievais 24 www2.fcsh.unl.pt/iem/medievalista 
campo que habían heredado con sus hermanos y parientes de su tío, el presbítero $\mathrm{Habze}^{49}$.

Estos presbíteros fueron los protagonistas de muchos de esos actos jurídicos recogidos en los documentos y también los testigos de otros que con su firma daban fe de la relevancia de algunas de las transacciones llevadas a cabo sobre propiedades de la comunidad o de los acuerdos conseguidos tras un proceso judicial. Es cierto, como asegura W. Davies, que es difícil hacerse una idea exacta de la escala de propiedad que estos presbíteros podrían haber tenido ${ }^{50}$. Es muy difícil generalizar porque hay ejemplos de todo tipo en este sentido: presbíteros de una capacidad patrimonial relevante, así como otros en los que los datos que poseemos hablan de pequeñas propiedades, muchas de ellas compartidas con el resto de los miembros de su propia familia ${ }^{51}$. Lo que sí se puede afirmar es que, en la mayor parte de los casos, los bienes de estos presbíteros mencionados en la documentación terminaron engrosando el patrimonio de alguno de los monasterios, principalmente el de Santiago de Valdevimbre y el de los Santos Justo y Pastor durante el siglo X, sin olvidar algún otro como el de San Juan Bautista y Santa María de León, fundado por el conde Munio Fernández, aunque éste ya en el siglo XI ${ }^{52}$. Tras las transacciones de propiedad hacia los monasterios por parte de los presbíteros estaba una estrategia de vinculación de éstos hacia estas instituciones eclesiásticas que representaban un grupo de poder importante en la zona y que estaban a su vez vinculados con el poder central. De manera que los presbíteros a través de esa vinculación alcanzaban un mayor prestigio dentro de sus propias comunidades y les situaba en una posición de intermediarios entre las bases sociales de las comunidades campesinas a las que pertenecían y los monasterios a los que entregaban tierras y bienes $^{53}$. Con estos datos que se han perfilado, habría que decir que durante el siglo X y

\footnotetext{
${ }^{49}$ CatLeón II, doc. 327.

50 DAVIES, Wendy - "Local priests in northern Iberia”. in PATZOLD, Steffen y VAN RHIJN, Carine (eds.) - Men in the Middle. Local Priests in Early Medieval Europe. Berlin: De Gruyter, (en prensa).

${ }^{51}$ Entre los primeros, los ya mencionados Berulfo o Speraindeo que estuvieron vinculados al monasterio de los Santos Justo y Pastor, o el presbítero Julián que hizo donación de un gran patrimonio, vid. CatLeón II, doc. 278 y doc. 279. Entre los segundos, el presbítero Rapinato y su sobrino Lub, o el presbítero Abolbalite, vid. CatLeón II, doc. 283 y doc. 418.

${ }^{52}$ CatLeón III, doc. 865.

53 I. Martín Viso pone el acento en esta relación clientelar de los presbíteros que marcaría un fortalecimiento de su posición en la propia comunidad, vid. MARTíN VISO, Iñaki - Poblamiento y
}

Medievalista online № 18| Julho - Dezembro 2015 ๑ IEM - Instituto de Estudos Medievais 25 www2.fcsh.unl.pt/iem/medievalista 
la primera mitad del siglo XI los presbíteros de esta zona, junto a los monasterios de Valdevimbre y el de los Santos Justo y Pastor, se conformaron como un grupo de elite que acumuló bienes accediendo a los recursos del paisaje que en inicio estuvieron en manos de las comunidades locales, transformando el equilibrio social que había habido en el seno de éstas, pasando estos recursos agrícolas y ganaderos a estar controlados por estas elites mencionadas.

En el segundo cuadro encontramos referencias numerosas de presbíteros que han actuado como testigos y confirmantes de documentos, así como notarios en algunos de ellos. De un total de 150 documentos que están relacionados con el espacio de Ardón y Valdevimbre, pues hacen alusión a propiedades en esta zona o a individuos que poseen bienes en este espacio, 83 corresponden a menciones de presbíteros. Hay un total de 184 menciones de nombres, algunos de los cuales son la misma persona que se reitera en diferentes documentos en esas labores de confirmación o como notario que redactaba el documento. De esas 184 menciones, hay 111 nombres diferentes, de los cuales al menos 42 aparecen como notarios. Todos estos datos revelan un alto número de menciones de estos presbíteros en la zona de Valdevimbre y Ardón y sus espacios circundantes. Los presbíteros del primer cuadro son más fácilmente identificables y somos capaces de ver qué tipo de relación establecieron con sus propias comunidades y con algunos de los monasterios de la zona; pero en el caso del segundo cuadro esta labor es más complicada por la generalidad de los datos. En tan sólo dos de las 184 menciones disponemos de alguna pista más, aunque éstas tampoco ayuden demasiado a resolver quiénes eran. En el año 952 se nombra a Nembrel presbiter de Auctarios como testigo de una venta al monasterio de los Santos Justo y Pastor de Ardón ${ }^{54}$. Algo parecido tenemos en el otro ejemplo, un documento del año 980 donde aparece como confirmante Pelagius, presbiter de Domnos Sanctos, y en el que el obispo de León donaba también al monasterio de Ardón la mitad de una corte que había confiscado al monje Caceme a quien se había acusado de fornicación ${ }^{55}$. De estos dos casos aislados, exceptuando el caso de Pelayo que es fácilmente identificable como presbítero en

estructuras sociales en el norte de la Península Ibérica, siglos VI-XIII. Salamanca: Ediciones Universidad de Salamanca, 2000, p. 197.

${ }^{54}$ CatLeón I, doc. 254.

${ }^{55}$ CatLeón II, doc. 479.

Medievalista online № 18| Julho - Dezembro 2015 @ IEM - Instituto de Estudos Medievais 26 www2.fcsh.unl.pt/iem/medievalista 
Sahagún, el caso de Nembrel no revela mucho puesto que el topónimo es de lo más usual y por tanto de difícil localización en la zona.

Con todo, la abundancia de referencias a estos presbíteros para esta zona, algunos de ellos bien relacionados con el poder central, otros situados en espacios de poder intermedios y con propiedades en la zona de estudio, no hacen más que situarnos en un escenario de diversificación social en el seno de las comunidades locales que se había ido produciendo a lo largo del siglo $\mathrm{X}$ y que no va a disminuir en la primera mitad del siglo XI.

\section{Conclusiones}

El análisis de la documentación referente al área del Páramo leonés que se centra en el espacio de Valdevimbre y Ardón para el siglo X y la primera mitad del siglo XI, permite vislumbrar que las comunidades campesinas asentadas en esa zona se encontraban en un proceso avanzado de diferenciación social y en contacto con algunas instituciones eclesiásticas y magnates laicos vinculados al poder central, que progresivamente fueron adquiriendo bienes $\mathrm{y}$ propiedades que anteriormente pertenecieron y fueron controlados por los miembros de estas comunidades. Todo este cúmulo de transformación de equilibrios dentro de las comunidades estuvo enmarcado en el más amplio proceso de feudalización de la sociedad leonesa, cuyas comunidades campesinas se fueron incorporando al ámbito político de la monarquía astur en su avance hacia el sur. Es en este escenario en el que debemos encuadrar el alto número de referencias a presbíteros que ha conservado la documentación leonesa del espacio de Valdevimbre y Ardón. Esta abundancia de menciones se ha de entender como uno de los elementos que nos alertan del grado de desigualdad social que se fue produciendo en las comunidades campesinas que entraron en la esfera política del poder central y de aquellos grupos de poder que estaban conectados con él y que paulatinamente fueron adquiriendo propiedades en la zona a través de los vínculos que establecieron con algunos de estos presbíteros, como representantes de una elite local que pretendía afianzar su posición en sus propias comunidades. Algunos de ellos, hemos visto que incluso pudieron llegar a posiciones privilegiadas, como el caso de Sendino Puricéliz, obispo de León.

Medievalista online № 18| Julho - Dezembro 2015 @ IEM - Instituto de Estudos Medievais 27 www2.fcsh.unl.pt/iem/medievalista 
Sin la notoriedad de éstos y con un menor número de referencias documentales, otro de los elementos que ilustra ese cambio en la transformación de la jerarquía social de las comunidades es la aparición de boni homines; también personajes de prestigio dentro de la comunidad, que actuaron como intermediarios en los litigios que se produjeron entre los miembros de la comunidad y algunos de los grupos de poder que se relacionaron con las comunidades de Valdevimbre y Ardón, ya fueran estos los monasterios de los Santos Justo y Pastor, el de Santiago de Valdevimbre o algunos magnates como Sancha Muñiz.

Como hemos podido observar gracias a los documentos, las relaciones entre estas elites mencionadas y las comunidades locales tuvieron una dimensión política en la medida en que se produjeron también cambios en la ubicación de los lugares elegidos para la resolución de conflictos entre ellos. La capital leonesa aparece mencionada como lugar recurrente e identificable en un número mayor de veces frente a otros espacios de reunión. Allí se dirimieron casos relevantes por el estatus social de los intervinientes en los litigios o por la importancia de las propiedades que eran objeto de disputa. Esta preferencia en cuanto a escoger León como lugar privilegiado de reunión, no fue óbice para que los miembros de las comunidades tuvieran que desplazarse a litigar a tribunales condales o a espacios de dominio de los monasterios, viendo así alterada la posibilidad de resolver las disputas sobre propiedades que les pertenecían en los espacios pertenecientes a las propias comunidades.

Por tanto, tres elementos para el análisis que confirman la creciente desigualdad social que se produjo ya en el siglo $X$ en el seno de las comunidades locales de la zona de Valdevimbre y Ardón fruto de la relación de éstas con algunos monasterios y magnates asentados en la zona y, a través de estos, con el poder central astur-leonés.

\section{REFERENCIAS BIBLIOGRÁFICAS}

\section{Fuentes impresas:}

FERNÁNDEZ CONDE, Francisco Javier - El Libro de los Testamentos de la Catedral de Oviedo. Roma: Iglesia Nacional Española, 1971. 
Lugares de reunión, boni homines y presbiteros en Valdevimbre y Ardón en la Alta Edad Media • Fernando Luis Corral

HERRERO DE LA FUENTE, Marta - Colección diplomática del monasterio de Sahagún (857-1230), II (1000-1073). León: Centro de Estudios e Investigación San Isidoro, 1988.

RODRÍGUEZ GONZÁLEZ, Ángel - “El tumbo del monasterio de San Martín de Castañeda”. Archivos Leoneses. León. 39-40 (1966), pp. 181-352.

RUIZ ASENCIO, José Manuel - Colección documental del archivo de la Catedral de León (775-1230), III (986-1031). León: Centro de Estudios e Investigación San Isidoro, 1987.

RUIZ ASENCIO, José Manuel, Colección documental del archivo de la Catedral de León (775-1230), IV ((1032-1109). León: Centro de Estudios e Investigación San Isidoro, 1987.

SÁEZ, Emilio - Colección documental del archivo de la Catedral de León (775-1230), I (775-952). León: Centro de Estudios e Investigación San Isidoro, 1987.

SÁEZ, Emilio y SÁEZ SÁNCHEZ, Carlos - Colección documental del archivo de la Catedral de León (775-1230), II (935-985). León: Centro de Estudios e Investigación San Isidoro, 1987.

VALDÉS GALLEGO, Juan Antonio - El Liber Testamentorum Ovetensis. Estudio filológico y edición. Oviedo: Real Instituto de Estudios Asturianos, 1999.

\section{Bibliografía / Estudios:}

ÁLVAREZ ÁLVAREZ, César - "El monasterio de Valdevimbre (siglos IX-XII)”. in DÍAZ Y DÍAZ, Manuel y DÍAZ DE BUSTAMANTE, Mercedes (eds.) - Estudios dedicados a José María Fernández Catón. León: Centro de Estudios e Investigación San Isidoro, 2004, pp. 41-64.

Medievalista online № $18 \mid$ Julho - Dezembro 2015 @ IEM - Instituto de Estudos Medievais 29 www2.fcsh.unl.pt/iem/medievalista 
ÁLVAREZ BORGE, Ignacio - Poder y relaciones sociales en Castilla en la Edad Media. Los terriotiros entre el Arlanzón y el Duero en los siglos X al XIV. Salamanca: Junta de Castilla y León, 1996.

ANDRADE CERNADAS, José Manuel - "Villas regias y asambleas judiciales entre los siglos X y XI: el caso de Larín”. Signum. Pampulha-Belo Horizonte. 12, n. 2 (2011), pp. 18-35.

CARVAJAL CASTRO, Álvaro - "La construcción de una sede regia: León y la identidad política de los reyes asturleoneses en la crónica de Sampiro y en los documentos”. e-Spania [en ligne]. 18 (junio 2014). 4 Jun. 2014 [Consult. 3 Sept. 2014]. Disponible en http://e-spania.revues.org/23714; DOI: 10.4000/e-spania.23714.

DAVIES, Wendy - Small Worlds: The Village Community in Early Medieval Brittany. Berkeley-Los Angeles: University of California Press, 1988.

DAVIES, Wendy - "Judges and judging: truth and justice in northern Iberia on the eve of the millennium”. Journal of Medieval History. Southampton. 36:3 (2010), pp. 193203.

DAVIES, Wendy - "Summary Justice and Seigneurial Justice in Northern Iberia on the Eve of the Milennium”. The Haskins Society Journal. Woodbridge, Suffolk. 22 (2010), pp. 43-58.

DAVIES, Wendy - "Settling Disputes in Early Medieval Spain and Portugal: a Contrast with Wales and Brittany?”. in GRIFFITHS, Ralph A., SCHOFIELD, Phillipp R. (eds.) Wales and the Welsh in the Middle Ages. Cardiff: University of Wales Press, 2011, pp. 89-107.

DAVIES, Wendy - "Local priests in northern Iberia”. in PATZOLD, Steffen y VAN RHIJN, Carine (eds.) - Men in the Middle. Local Priests in Early Medieval Europe. Berlin: De Gruyter, (en prensa).

Medievalista online № $18 \mid$ Julho - Dezembro 2015 @ IEM - Instituto de Estudos Medievais 30 www2.fcsh.unl.pt/iem/medievalista 
Lugares de reunión, boni homines y presbiteros en Valdevimbre y Ardón en la Alta Edad Media • Fernando Luis Corral

DAVIES, Wendy - Windows on Justice. Record and practice in the courts of northern Iberia at the end of the first millennium, Part II, chapter 6: People and Role Play, (en prensa).

ESTEPA DÍEZ, Carlos - Estructura social de la ciudad de León (Siglos XI-XIII). León: Centro de Estudios e Investigación San Isidoro, 1977.

ESTEPA DÍEZ, Carlos - "Poder y propiedad feudales en el período astur: las mandaciones de los Flainez en la montaña leonesa”. in Miscel.làlia en Homenatge al P. Agustí Altisent, Tarragona: Diputació de Tarragona, 1991, pp. 285-328.

FERNÁNDEZ CATÓN, José María - "La nodicia de kesos y los problemas de la documentación del siglo x sobre el origen de los monasterios independientes de Rozuela y Cillanueva”. in Orígenes de las lenguas romances en el reino de León, siglos IX-XII, vol. I. León: Centro de Estudios e Investigación San Isidoro, 2004, pp. 35-85.

LUIS CORRAL, Fernando - Villavicencio en la Edad Media. Propiedad y jurisdicción en los valles del Cea y del Valderaduey. Valladolid: Diputación de Valladolid, 2003.

MCKITTERICK, Rosamond - The Carolingians and the Written Word. Cambridge: Cambridge University Press, 1995.

MARTÍN VISO, Iñaki - "La feudalización del Valle de Sanabria (siglos X-XIII)”. Studia Historica. Historia Medieval. Salamanca. 11 (1993), pp. 35-56.

MARTÍN VISO, Iñaki - Poblamiento y estructuras sociales en el norte de la Península Ibérica, siglos VI-XIII. Salamanca: Ediciones Universidad de Salamanca, 2000.

MARTÍN VISO, Iñaki - Fragmentos del Leviatán. La articulación política del espacio zamorano en la Alta Edad Media. Zamora: Instituto de Estudios zamoranos "Florián de Ocampo”, 2002.

Medievalista online $N^{\circ} 18$ | Julho - Dezembro 2015 ๑ IEM - Instituto de Estudos Medievais 31 www2.fcsh.unl.pt/iem/medievalista 
MARTÍNEZ SOPENA, Pascual - “La justicia en la época asturleonesa: entre el Liber y los mediadores sociales”. in Rodríguez, Ana (ed.) - El lugar del campesino. En torno a la obra de Reyna Pastor. Valencia: Universitat de València, 2007, pp. 239-260.

MÍNGUEZ FERNÁNDEZ, José María - “Justicia y poder en el marco de la feudalización de la sociedad leonesa”. in La Giustizia nell'alto medioevo (secoli IX-XI). 11-17 aprile 1996. Settimane di Studio del Centro Italiano di Studi sull'alto Medioevo. Spoleto: Centro Italiano di Studi sull’alto Medioevo. XLIV (1997), pp. 491-548.

MÍNGUEZ FERNÁNDEZ, José María - “Poderes locales en el espacio central leonés durante el periodo astur”. Territorio, Sociedad y Poder. Oviedo. Anejo 2 (2009), pp. 199-214.

PORTELA SILVA, Ermelindo y PALLARES MÉNDEZ, Ma. Carmen - "La villa por dentro. Testimonios galaicos de los siglos X y XI”. Studia Historica. Historia Medieval. Salamanca. 16 (1998), pp. 13-43.

RODRÍGUEZ FERNÁNDEZ, Justiniano - El monasterio de Ardón. Estudio histórico sobre los centros monásticos medievales de Cillanueva y Rozuela. León: Centro de Estudios e Investigación de San Isidoro, 1964.

SALRACH I MARÈS, José María - "Prácticas judiciales, transformación social y acción política en Cataluña (siglos IX-XIII)”. Hispania. Madrid. LVII/3, 197 (1997), pp. 1009-1048.

SÁNCHEZ PARDO, José Carlos - Territorio y poblamiento en Galicia entre la Antigüedad y la Plena Edad Media. Santiago de Compostela: Servicio de Publicaciones de la Universidad de Santiago de Compostela, 2008. Tesis doctoral publicada en CD. [Consult. On-line 08 Agost. 2014].

TORRES SEVILLA, Margarita - "Munio Fernández y su descendencia. Vida, patrimonio y política familiar de un conde de Astorga”. Astorica. Astorga. 14 (1995), pp. 149-172.

Medievalista online $N^{\circ} 18$ | Julho - Dezembro 2015 ๑ IEM - Instituto de Estudos Medievais 32 www2.fcsh.unl.pt/iem/medievalista 
VILLALOBOS, María Luisa y GONZÁLEZ, J. Ignacio - “San Justo y Pastor de Ardón. Problemas históricos y patrimonio monástico”. in Semana de Historia del Monacato Cántabro-Astur-Leonés. Oviedo, 1982, pp. 155-173.

TORRES SEVILLA, Margarita y GALVÁN FREILE, Fernando - “La condesa Doña Sancha. Una nueva aproximación a su figura”. Medievalismo. Murcia. 5 (1995), pp. 930.

WICKHAM, Chris - “Comunidades rurales y señorío débil: el caso del norte de Italia, 1050-1250”. in ÁLVAREZ BORGE, Ignacio (coord.) - Comunidades locales y poderes feudales en la Edad Media. Logroño: Universidad de La Rioja, 2001, pp. 395-416.

WICKHAM, Chris - "Espacio y sociedad en los conflictos campesinos en la Alta Edad Media”. in RODRÍGUEZ, Ana (ed.) - El lugar del campesino. En torno a la obra de Reyna Pastor. Valencia: Universitat de València y CSIC, 2007, pp. 33-60.

\section{COMO CITAR ESTE ARTIGO}

\section{Referência electrónica:}

LUIS CORRAL, Fernando - “Lugares de reunión, boni homines y presbíteros en Valdevimbre y Ardón en la Alta Edad Media”.

Medievalista [Em linha]. №18 (Julho - Dezembro 2015). [Consultado dd.mm.aaaa].

Disponível em http://www2.fcsh.unl.pt/iem/medievalista/MEDIEVALISTA18/corral1805.html ISSN 1646-740X. 
Lugares de reunión, boni homines y presbiteros en Valdevimbre y Ardón en la Alta Edad Media - Fernando Luis Corral

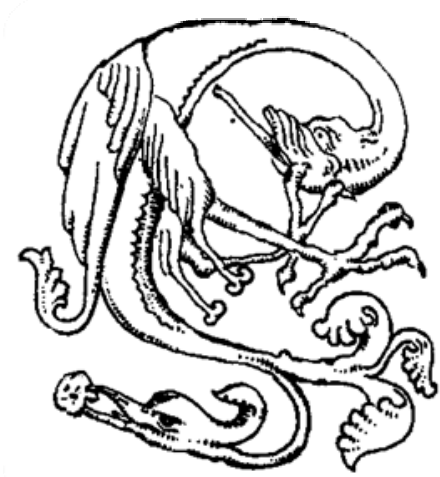

Medievalista online № 18| Julho - Dezembro 2015 @ IEM - Instituto de Estudos Medievais 34 www2.fcsh.unl.pt/iem/medievalista 